University of Texas at El Paso

\title{
DigitalCommons@UTEP
}

Open Access Theses \& Dissertations

2011-01-01

\section{The Reactivity of Potassium Carbanions with Epoxides}

Christina Dorado

University of Texas at El Paso, calvarado4@miners.utep.edu

Follow this and additional works at: https://digitalcommons.utep.edu/open_etd

Part of the Chemistry Commons

\section{Recommended Citation}

Dorado, Christina, "The Reactivity of Potassium Carbanions with Epoxides" (2011). Open Access Theses \& Dissertations. 2272. https://digitalcommons.utep.edu/open_etd/2272

This is brought to you for free and open access by DigitalCommons@UTEP. It has been accepted for inclusion in Open Access Theses \& Dissertations by an authorized administrator of DigitalCommons@UTEP. For more information, please contact lweber@utep.edu. 
THE REACTIVITY OF POTASSIUM CARBANIONS WITH EPOXIDES

\author{
CHRISTINA DORADO
}

Department of Chemistry

APPROVED:

James M. Salvador, Ph.D., Chair

Katja Michael, Ph.D.

Carl W. Dirk, Ph.D.

Shizue Mito, Ph.D.

Felicia S. Manciu, Ph.D.

Benjamin C. Flores, Ph.D.

Acting Dean of the Graduate School 
Copyright (C)

by

Christina Dorado

2011 


\section{Dedication}

This dissertation is dedicated to my parents Maria Cristina and Raul Ruben Alvarado

to my brother and sister, Ruben and Erika,

to my grandmother Emma Morales

and to my husband Arturo Dorado. 
THE REACTIVITY OF POTASSIUM CARBANIONS WITH EPOXIDES

by

CHRISTINA DORADO, B.S.

\author{
Dissertation \\ Presented to the Faculty of the Graduate School of \\ The University of Texas at El Paso \\ in Partial Fulfillment \\ of the Requirements \\ for the Degree of
}

DOCTOR OF PHILOSOPHY

Department of Chemistry

THE UNIVERSITY OF TEXAS AT EL PASO

August 2011 


\section{Acknowledgements}

I would like to express my appreciation to my advisor, Dr. James M. Salvador, for his guidance and support throughout this research project. I would also like to thank the members of my committee, Dr. Katja Michael, Dr. Carl W. Dirk, Dr. Shizue Mito and Dr. Felicia S. Manciu, for supervising the progess of this research work as well as my academic development. For their guidance and support, I would like to thank Dr. Benjamin Flores, Ariana Arciero and Sara Rodriguez. I would like to express my gratitude to the University of Texas at El Paso Graduate School, Department of Chemistry and the Louis Stokes Alliance for Minority Participation Bridge to the Doctorate Fellowship for their financial support. I would also like to thank Grace Awad and Lucema Armenta for their assistance. I would like to acknowledge the technical support and advice given by Dr. Jorge Gardea-Torresdey, Dr. Luis Echegoyen, Dr. Wen-Yee Lee, Dr. Bonnie Gunn, Dr. Hiram Castillo, Dr. Milka Montes, Dr. David Chavez, Dr. Roberto De La Torre, Danisha Rivera-Nazario, Arturo Montes and Saideh Mortazavi. I would also like to express my gratitude to BASF for generously donating necessary reagents. I would like to thank my family and friends for their love and encouragement throughout this endeavor and in my life. I would like to especially thank my mother, Maria Cristina Alvarado, for teaching me the value of higher education and my father, Raul Ruben Alvarado, for teaching me the importance of communication and for their joined love and support. I would also like to thank my grandmother, Emma Morales, for her love and wisdom. I would like to thank my sister, Erika, for her love and inspiration in my life and my brother, Ruben, for his love and support. Finally, I would like to express my sincerest gratitude to my husband, Arturo Dorado, for his patience, understanding, support and love. 


\begin{abstract}
The reaction of $\alpha$-cumylpotassium and cyclohexene oxide produces transcumylcyclohexanol in high yield in the presence of excess cumene. Reactions of 1.1 and 2.0 equivalents of cumene with one equivalent of $n$-butylpotassium to make $\alpha$-cumylpotassium were shown to take several days to reach a maximum yield in the subsequent reaction of $\alpha$ cumylpotassium and cyclohexene oxide. Although it was initially hypothesized that the high yield was attributed to the interaction of the potassium with the aromatic rings of the $\alpha$-cumyl anion and the excess cumene, which was confirmed by molecular modeling studies, these reactions demonstrated that no large excess of aromatic solvents were needed. Substituting benzene and tert-butylbenzene for cumene in this reaction gave lower yields of product.

Cyclohexene oxide reacted with $n$-butylpotassium to unexpectedly produce 2butylcyclohexanone in a $2 \%$ isolated yield or in a $10 \%$ isolated yield of its semi-carbazone derivative. Based on the literature, we hypothesized that we produced 2-butylcyclohexanone by first opening the epoxide ring of cyclohexene oxide by $\mathrm{S}_{\mathrm{N}} 2$ substitution with $n$-butylpotassium to give the alkoxide of trans-2-butylcyclohexan-1-ol as observed in the reaction of cyclohexene oxide and $\alpha$-cumylpotassium. Next, a second equivalent of $n$-butylpotassium reacted with cyclohexene oxide to produce a carbene alkoxide. Finally, the carbene alkoxide oxidized the alkoxide of trans-2-butylcyclohexan-1-ol to 2-butylcyclohexanone. This mechanism implies that a greater than $33 \%$ yield is not possible.
\end{abstract}

The reaction of 2-methyl-1,2-epoxycyclohexane with $n$-butylpotassium and the reaction of cyclohexene oxide with sec-butyllithium did not lead to any ring opening products. 


\section{Table of Contents}

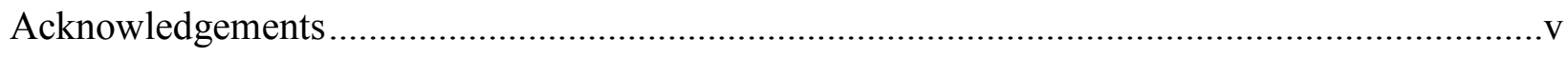

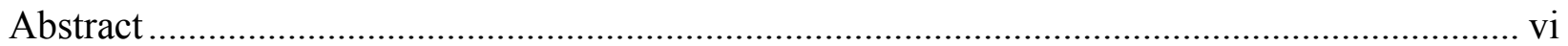

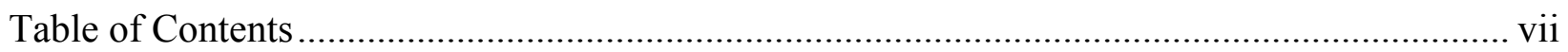

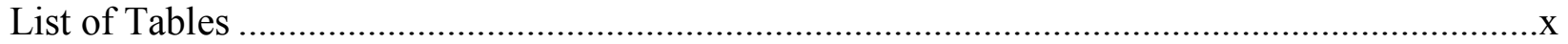

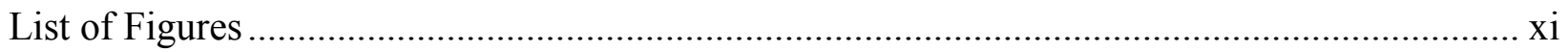

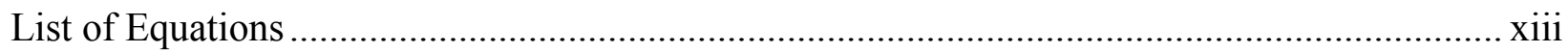

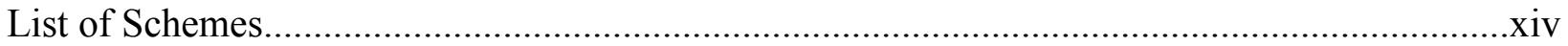

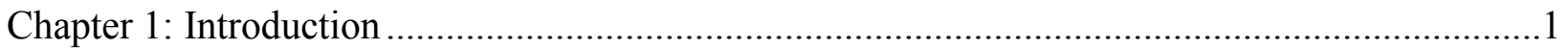

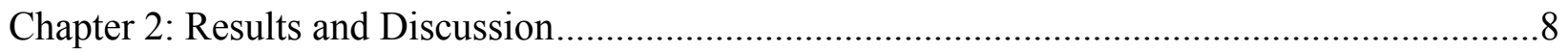

2.1 Molecular Modeling Studies of $\alpha$-Cumylpotassium, Lithium, and Sodium........................8

2.2 Solvent Effect of Cumene Substitution with Benzene and tert-Butylbenzene...................10

2.2.1 Substitution of Cumene with Benzene..............................................................

2.2.2 Substitution of Cumene with tert-Butylbenzene............................................12

2.3 Kinetic Studies on the Reaction of $\alpha$-Cumylpotassium with Cyclohexene Oxide..............13

2.3.1 Production of trans-Cumylcyclohexanol in the Presence of 1.1 Equivalents of

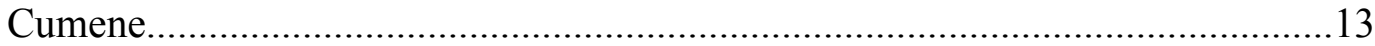

2.3.2 Production of trans-Cumylcyclohexanol in the Presence of 2.0 Equivalents of

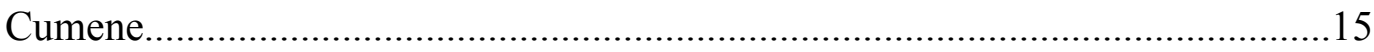

$2.4 \quad$ Reactivity of Other Organopotassium Species...........................................................17

2.4.1 Reaction of $n$-Butylpotassium and Cyclohexene Oxide..................................17

2.4.2 Reaction of $n$-Butyllithium and Cyclohexene Oxide........................................20

2.4.3 Isolation and Analysis of 2-Butylcyclohexanone........................................21

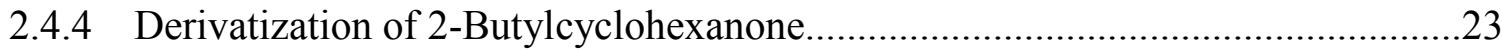

2.4.5 Hypotetical Mechanism for Formation of 2-Butylcyclohexanone.......................25 
2.4.6 Reaction of $s e c$-Butylpotassium and Cyclohexene Oxide...................................30

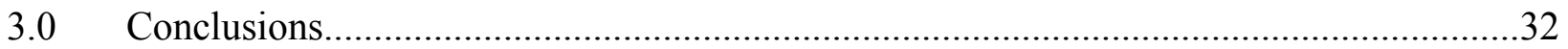

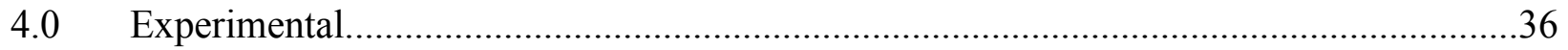

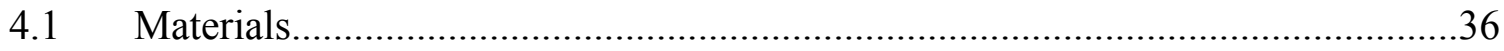

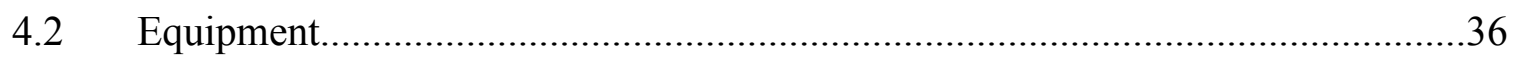

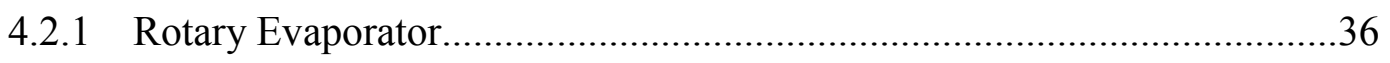

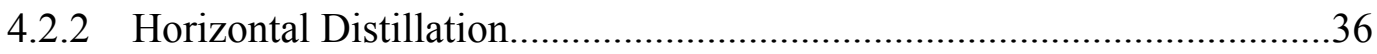

4.2.3 Chiral Column High Performance Liquid Chromatography.....................36

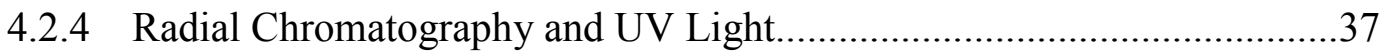

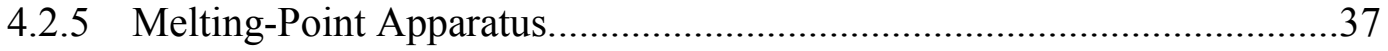

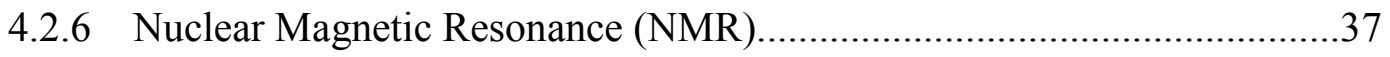

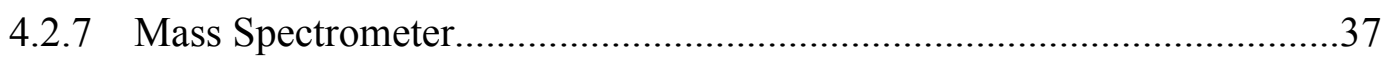

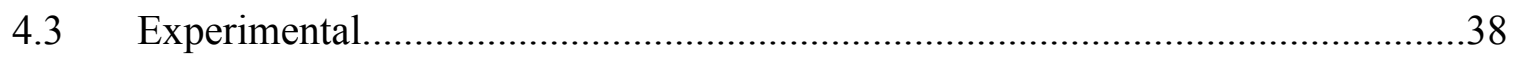

4.3.1 Attempted Synthesis of trans-Cumylcyclohexanol in the Presence of

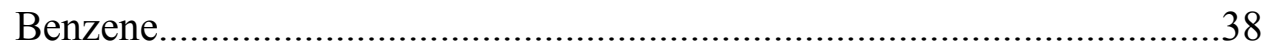

4.3.2 Attempted Synthesis of trans-Cumylcyclohexanol in the Presence of

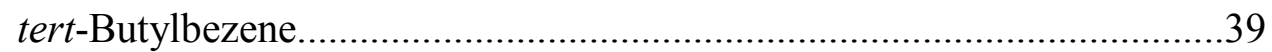

4.3.3 Synthesis of trans-Cumylcyclohexanol with 1.1 Equivalents of

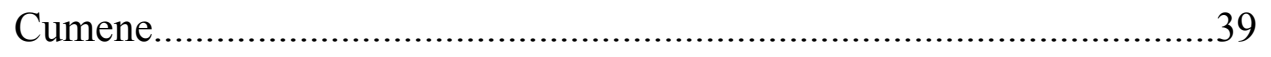

4.3.4 Synthesis of trans-Cumylcylohexanol with 2.0 Equivalents of

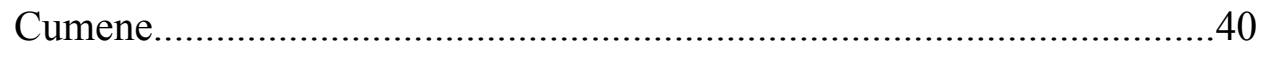

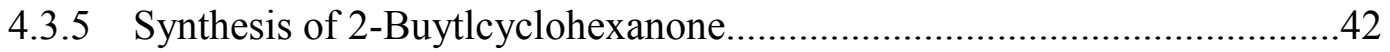

4.3.6 Synthesis of 2-Butylcyclohexanone Semicarbazone...............................43

4.3.7 Attempted Synthesis of Cyclohexanone...........................................43

4.3.8 Attempted Synthesis of 2-Butyl-1-Methylcyclohexan-1-ol......................44

4.3.9 Reaction of sec-Butylpotassium and Cyclohexene Oxide........................44 


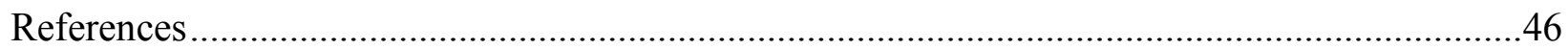

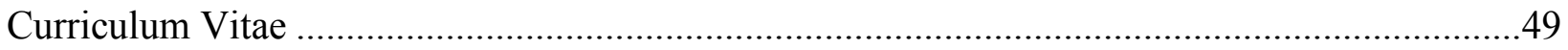




\section{List of Tables}

Table 2.1: 1.1 Equivalents of Cumene, Kinetic Experiment Conditions and Results .................. 14

Table 2.2: 2.0 Equivalents of Cumene, Kinetic Experiment Conditions and Results................... 16 


\section{List of Figures}

Figure 1.1: Super-Base or LiCKOR Reagent........................................................................

Figure 1.2: Interaction of Potassium with Aromatic Rings of Cumene..........................................6

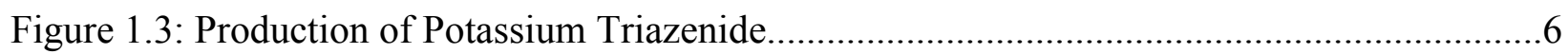

Figure 1.4: Structure of Potassium Dihydroborate and Toluene.....................................................6

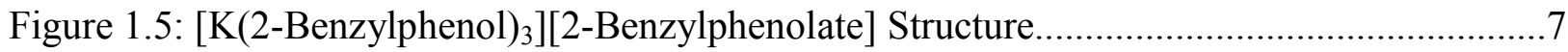

Figure 1.6: Synthesis and Structure of Potassium Bridged Borole Compound.................................

Figure 2.1: Optimization Calculations of $\alpha$-Cumylpotassium and Cumene.....................................8

Figure 2.2: Optimization Calculations of $\alpha$-Cumyllithium and Cumene........................................

Figure 2.3: Optimization Calculations of $\alpha$-Cumylsodium and Cumene

Figure 2.4: Chiral HPLC Chromatogram and Data for TCC Synthesis in the Presence of

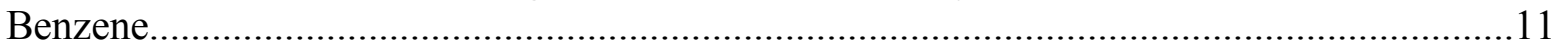

Figure 2.5: Chiral HPLC Chromatogram and Data for a TCC Standard Solution.........................11

Figure 2.6: Chiral HPLC Chromatogram and Data for TCC Synthesis in the Presence of tertButylbenzene..................................................................................................................12

Figure 2.7: Time vs. Percent Yield of the 1.1 and 2.0 Equivalents of Cumene Reactions.............16

Figure 2.8: ${ }^{13} \mathrm{C}$ NMR Spectrum of Crude Product from the Reaction of $n$-Butylpotassium and

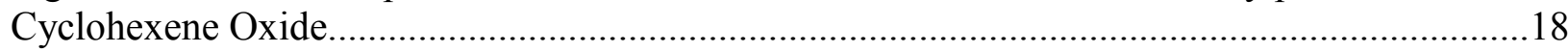

Figure 2.9: ${ }^{1} \mathrm{H}$ NMR Spectrum of Crude Product from the Reaction of $n$-Butylpotassium and

Cyclohexene Oxide............................................................................................................19

Figure 2.10: DEPT-135 Spectrum of Crude Product from the Reaction of $n$-Butylpotassium and

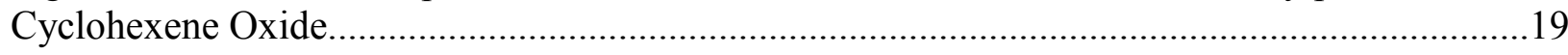

Figure 2.11: ${ }^{13} \mathrm{C}$ NMR Spectrum of Crude Product from the Reaction of $n$-Butyllithium and

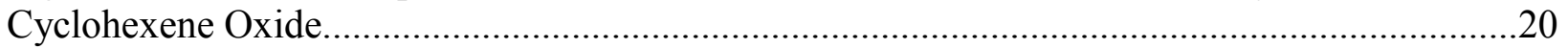

Figure 2.12: ${ }^{13} \mathrm{C}$ NMR Spectrum of First Fraction Isolated by Radial Chromatography..............21

Figure 2.13: Mass Spectrum with Parent Peak for 2-Butylcyclohexanone...................................22 
Figure 2.14: ${ }^{13} \mathrm{C}$ NMR of 2-Butylcyclohexanone Semicarbazone............................................24

Figure 2.15: Calculated ${ }^{13} \mathrm{C}$ NMR for 2-Butylcyclohexanone Semicarbazone............................24

Figure 2.16: X-Ray Fluorescence of Potassium tert-Amylate.............................................25

Figure 2.17: ${ }^{13} \mathrm{C}$ NMR of Crude Product from the Reaction of $n$-Butylpotassium and Cyclohexene Oxide in the Presence of Cyclohexanol........................................28

Figure 2.18: ${ }^{13} \mathrm{C}$ NMR of Crude Product from the Reaction of $n$-Butylpotassium with 1-Methyl-

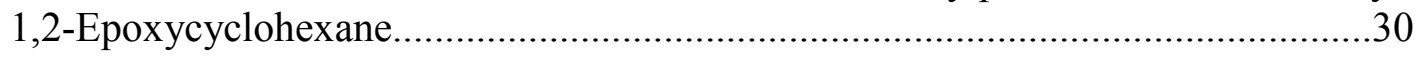

Figure 2.19: ${ }^{13} \mathrm{C}$ NMR of Crude Product from the Reaction of sec-Butylpotassium and






\section{List of Equations}

Equation 2.1: Calculation of Percent Yield for TCC Synthesized in the Presence of

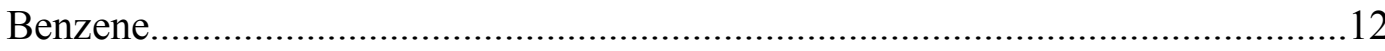

Equation 2.2: Calculation of Percent Yield for TCC Synthesized in the Presence of tert-

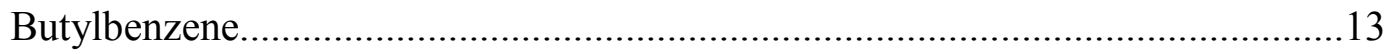




\section{List of Schemes}

Scheme 1.1: Reaction of Mono-Substituted Epoxides with Alkyl Lithium or Grignard Reagent to Produce the Corresponding Alcohol..................................................................

Scheme 1.2: Reaction of $n$-Buytllithium and Cyclohexene Oxide to Produce the Elimination Product.

Scheme 1.3: Reaction of $n$-Butyllithium and Cyclohexene Oxide in the Presence of $\mathrm{BF}_{3} \bullet \mathrm{Et}_{2} \mathrm{O}$ to Produce the Substitution Product. 2

Scheme 1.4: Reaction of $n$-Propyl Magnesium Bromide with Cyclohexene Oxide to Produce

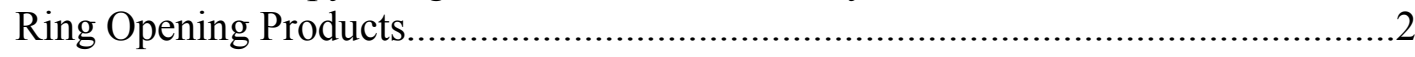

Scheme 1.5: Reaction of trans-2,3-Dimethyloxirane, tert-Butyl Magnesium Chloride, and Copper Cyanide to Produce a Ring Opening Product.... .2

Scheme 1.6: Reaction of Cyclohexene Oxide and Phenyl Magnesium Chloride in the Presence and Absence of Copper Iodide to Produce trans-2-Phenylcyclohexan-1-ol..............3

Scheme 1.7: Production of Trimethylsilyl Derivative of Tetrahydropyran.......................3

Scheme 1.8: Ring Opening Reaction of $\alpha$-Cumylpotassium and Cyclohexene Oxide to Produce trans-Cumylcyclohexanol (TCC).....

Scheme 1.9: Potassium-Lithium Ion Exchange Reaction of $n$-Butylltihium and Potassium tertAmylate.

Scheme 1.10: Synthesis of $\alpha$-Cumylpotassium from Cumene and $n$-Butylpotassium..................5

Scheme 1.11: Reaction of Three Equivalents of Cumene and $n$-Butylpotassium Followed by Cyclohexene Oxide to Produce TCC in High Yield.

Scheme 2.1: Substitution of Cumene with Other Aromatic Solvents in the Synthesis of TCC....10

Scheme 2.2: Substitution of Cumene with Benzene in the Synthesis of TCC.

Scheme 2.3: Substitution of Cumene with tert-Butylbenzene in the Synthesis of TCC.

Scheme 2.4: Reaction Scheme for Kinetic Experiments. 14

Scheme 2.5: Equilibrium of meta and para Metalated Cumene and the Thermodynamically Favored $\alpha$-Cumylpotassium... .15

Scheme 2.6: Reaction of $n$-Butylpotassium and Cyclohexene Oxide. 
Scheme 2.7: Reaction of $n$-Butylpotassium and Cyclohexene Oxide to Produce 2-Butylcyclohexanone.

Scheme 2.8: Reaction of 2-Butylcyclohexanone with Semicarbazide to Produce 2Butylcyclohexanone Semicarbazone. 23

Scheme 2.9: Rearrangement of Epoxides to Enolates Through a Carbene Intermediate...............26

Scheme 2.10: Reaction of a Secondary Metal Alkoxide with a Carbene to Produce a Ketone.....26

Scheme 2.11: Hypothesized Mechanism for the Production of 2-Butylcyclohexanone................27

Scheme 2.12: Reaction of $n$-Butylpotassium with Cyclohexene Oxide in the Presence of Cyclohexanol to Produce Cyclohexanone

Scheme 2.13: Reaction of 1-Methyl-1,2-Epoxycyclohexane with $n$-Butylpotassium to Produce 2Butyl-1-Methylcyclohexan-1-ol.

Scheme 2.14: Suspected Rearrangement of 1-Methyl-1,2-Epoxycyclohexane to the Corresponding Ketone. .29

Scheme 2.15: Production of sec-Butylpotassium 30

Scheme 3.1: Reaction of an Intermediate Dianion with a Carbene to Produce Cyclohexenol 


\section{Chapter 1: Introduction}

The creation of carbon-carbon bonds is an essential part of organic synthesis for the production of new molecules. Carbon-carbon bonds can be formed in nucleophilic reactions such as the nucleophilic substitution reaction of a carbon nucleophile with epoxides to produce 1,2difunctionalized molecules such as 1,2-amino alcohols, 1,2-diols, 1,2-mercapto alcohols and 1,2halohydrins ${ }^{1}$. These 1,2-difunctionalized molecules are utilized to produce natural products such as $( \pm)$-Puctaporonin $C$, a tetracyclic sesquiterpene ${ }^{2}$ as well as hydroxy-Freidinger lactams which are used to produce biologically active peptidomimietrics ${ }^{3}$.

The nucleophilic ring opening reaction of unsymmetric epoxides containing a primary carbon is regioselective and leads to substitution at the less substituted and less sterically hindered position in high yields ${ }^{4,5}$ (Scheme 1.1).

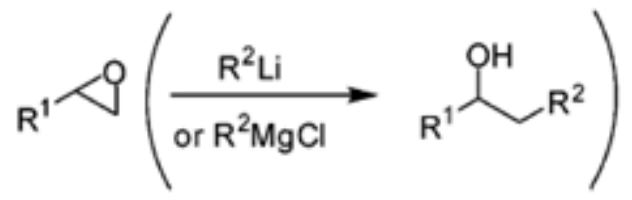

\section{Scheme 1.1 Reaction of Mono-Substituted Epoxides with Alkyl Lithium or Grignard Reagents to Produce the Corresponding Alcohol ${ }^{5}$.}

In contrast, when $n$-butyllithium reacts with cyclohexene oxide, an epoxide with secondary carbons, the elimination product is obtained exclusively (Scheme 1.2) ${ }^{6}$.

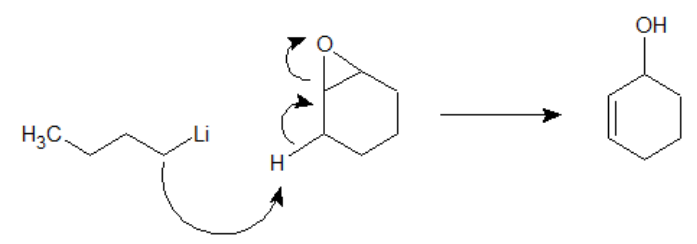

Scheme 1.2 Reaction of $\boldsymbol{n}$-Butyllithium and Cyclohexene Oxide to Produce the Elimination Product $^{6}$. 
In order to obtain the substitution product, organolithium reagents must be reacted with epoxides in the presence of a Lewis acid. When $n$-butyllithium and cyclohexene oxide are reacted in the presence of boron trifluoride etherate, 2-butylcyclohexanol can be obtained in a yield of $97 \%$ (Scheme1.3) ${ }^{7}$.

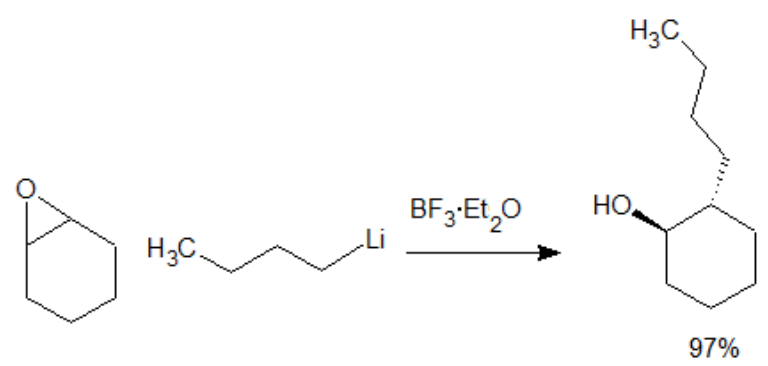

Scheme 1.3 Reaction of $n$-Butyllithium and Cyclohexene Oxide in the Presence of $\mathrm{BF}_{3} \bullet$ $\mathrm{Et}_{2} \mathrm{O}$ to Produce the Substitution Product ${ }^{7}$.

Grignard reagents must be converted to an organo-cuprate before reacting with secondary epoxides to give ring opening products (Schemes $1.4,1.5$, and 1.6) ${ }^{8-10}$. This is due to the fact that copper is less electropositive than lithium and magnesium, making the bond between copper and the alkyl group less polar ${ }^{4}$.

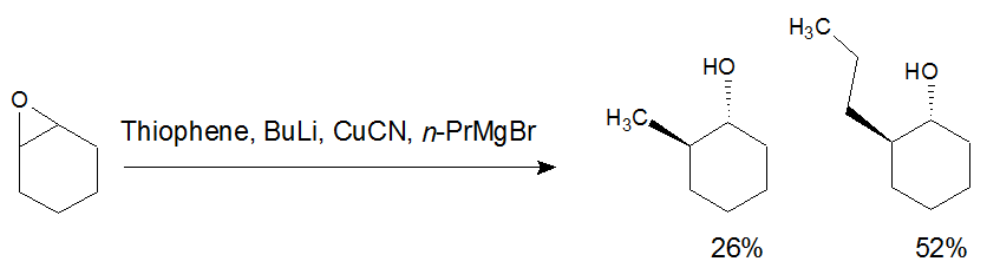

Scheme 1.4 Reaction of $\boldsymbol{n}$-Propyl Magnesium Bromide with Cyclohexene Oxide to Produce Ring Opening Products ${ }^{8}$.

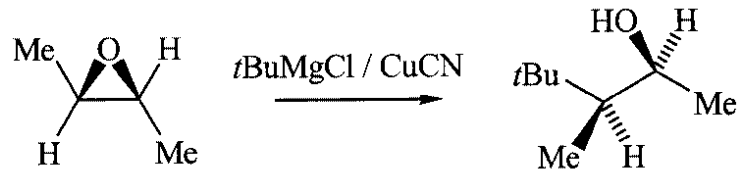

$31 \%$

Scheme 1.5 Reaction of trans-2,3-Dimethyloxirane, tert-Butyl Magnesium Chloride, and Copper Cyanide to Produce a Ring Opening Product'. 


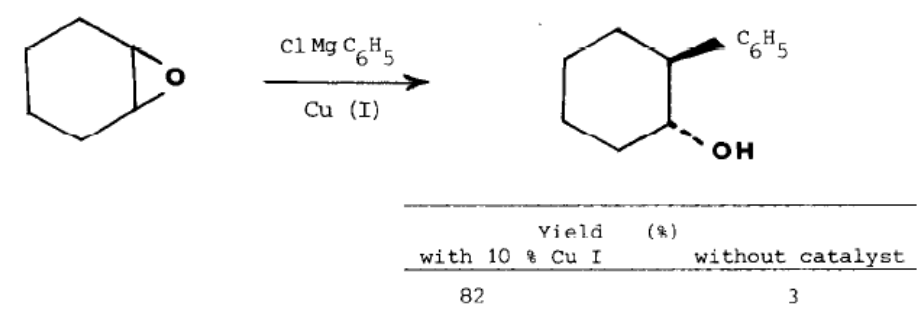

Scheme 1.6 Reaction of Cyclohexene Oxide and Phenyl Magnesium Chloride in the Presence and Absence of Copper Iodide to Produce trans-2-Phenylcyclohexan-1-ol ${ }^{10}$.

Literature describes the combination of a potassium alkoxide and butyl lithium as a "super-base" or LiCKOR-reagent with metalating capabilities (Figure 1.1) ${ }^{11}$.

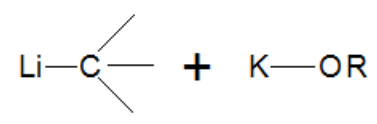

\section{Figure 1.1 Super-Base or LiCKOR Reagent ${ }^{11}$.}

When this reagent has been introduced to various hydrocarbons they undergo a hydrogen/metal exchange reaction or deprotonation ${ }^{11}$. Alkyl potassiums ${ }^{12,14,15}$ prepared in a similar manner ${ }^{11}$ have also been reacted with ferrocene ${ }^{12}, \alpha$-olefins ${ }^{13}$, toluene, cross-linked polystyrene derivatives ${ }^{14}$ and saturated ethers to produce the metalated products ${ }^{12-15}$. For example, in Scheme 1.7 tetrahydropyran is first reacted with $n$-butylpotassium to give the metalated product followed by reaction with chlorotrimethylsilane to give the trimethylsilyl derivative ${ }^{15}$.

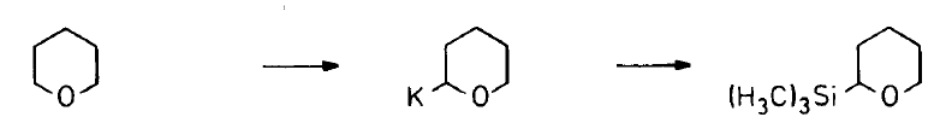

\section{Scheme 1.7 Production of Trimethylsilyl Derivative of Tetrahydropyran ${ }^{15}$.}

Based on this knowledge it may be expected that $n$-butylpotassium prepared this way ${ }^{11}$ would simply metalate an epoxide but this is not the case. In particular Comins and Salvador 
found that secondary epoxides react with $\alpha$-cumylpotassium to produce transcumylcyclohexanol (TCC) ${ }^{16}$ (Scheme 1.8).

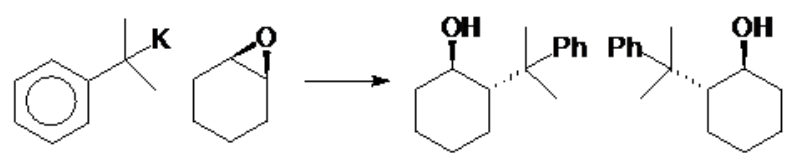

\section{Scheme 1.8 Ring Opening Reaction of $\alpha$-Cumylpotassium and Cyclohexene Oxide to Produce trans-Cumylcyclohexanol (TCC) ${ }^{16}$.}

Based on the reactivity of organolithium and magnesium reagents with cyclohexene oxide it would be expected that $\alpha$-cumylpotassium would not react with cyclohexene oxide in a nucleophilic substitution fashion but perhaps would perform elimination. It is therefore unusual that this tertiary organopotassium species can react with cyclohexene oxide in a substitution fashion without the need for activators such as boron trifluoride as is necessary for organolithiums or for conversion to organocuprates which are necessary for organomagnesium reagents.

In reality the reaction of $\alpha$-cumylpotassium and cyclohexene oxide to produce TCC (Scheme 1.8) consists of three reactions all done in one pot. First a potassium-lithium ion exchange reaction is completed to form $n$-butylpotassium (Scheme 1.9), followed by the reaction of $n$-butylpotassium and cumene to make $\alpha$-cumylpotassium (Scheme 1.10), after two days cyclohexene oxide is added, and after two hours the reaction is quenched with water and the desired, TCC, is obtained (Scheme 1.11).

The preparation of $n$-butylpotassium by a potassium-lithium ion exchange reaction avoids using highly reactive and unstable potassium metal (Scheme 1.9). 


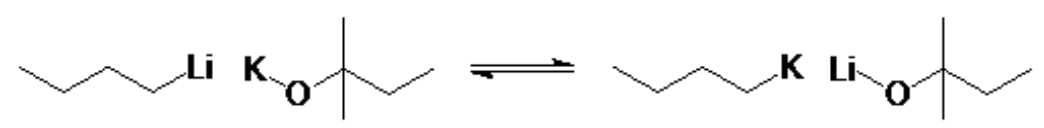

\section{Scheme 1.9 Potassium-Lithium Ion Exchange Reaction of $\boldsymbol{n}$-Butyllithium and Potassium tert-Amylate.}

Because $n$-butylpotassium is such a strong base it can deprotonate cumene at its benzilic position and on the phenyl ring (Scheme 1.10). It therefore takes two days to allow the equilibrium to favor deprotonation of the cumene at the benzilic position to make the $\alpha$-cumyl $\operatorname{anion}^{17}$.

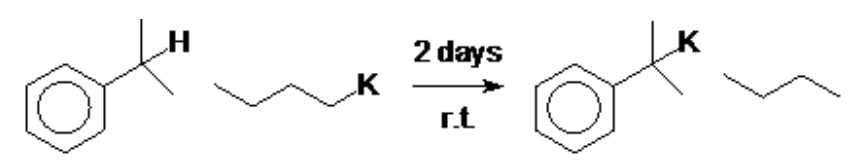

Scheme 1.10 Synthesis of $\alpha$-Cumylpotassium from Cumene and $n$-Butylpotassium ${ }^{17}$.

As shown in Scheme 1.11 in the reaction the yield increases proportionately with the amount of cumene used to $93 \%{ }^{16}$ with three equivalents.

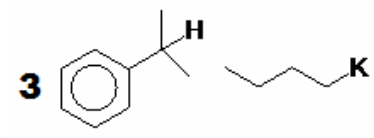

1. Two days/ r.t.

2. Cyclohexene oxide

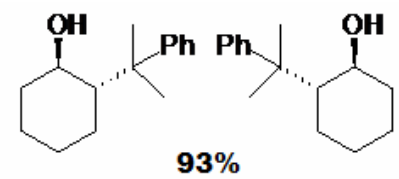

Scheme 1.11 Reaction of Three Equivalents of Cumene and $n$-Butylpotassium Followed by Cyclohexene Oxide to Produce TCC in High Yield ${ }^{16}$.

The initial hypothesis of why three equivalents of cumene are required for this reaction was that the $d$-orbitals of potassium were interacting with the aromatic portion of the solvent as presented in Figure 1.2. 


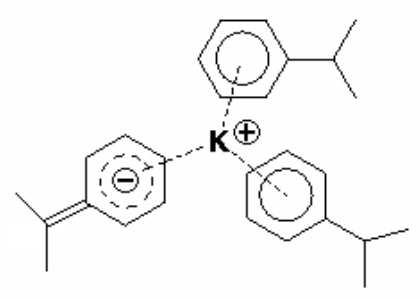

\section{Figure 1.2 Interaction of Potassium with Aromatic Rings of Cumene.}

There are various examples of the interaction of potassium with aromatic groups in the literature ${ }^{18-21}$. For example, after metalation of the triazene $\left.\left(\mathrm{C}_{6} \mathrm{H}_{3}-2,6-\left(\mathrm{C}_{6} \mathrm{H}_{2}-2,4,6-{ }^{i} \mathrm{Pr}_{3}\right)_{2}\right)_{2} \mathrm{~N}_{3} \mathrm{H}\right)$, interaction of potassium with the flanking arene rings of diaryltriazenido ligands is observed in the resulting alkali-metal salt (Figure 1.3) ${ }^{18}$.
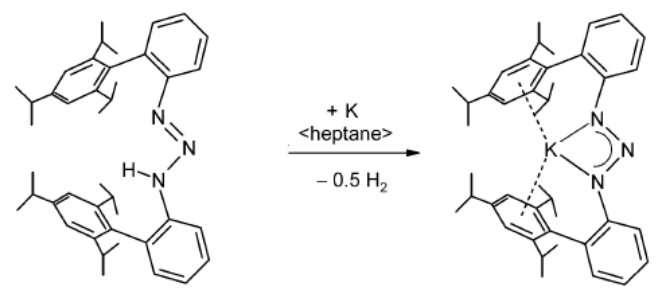

yield: $86 \%$

\section{Figure 1.3 Production of Potassium Triazenide ${ }^{18}$.}

Potassium is observed to interact with toluene, a solvent utilized in the formation of the potassium dihydroborate in Figure $1.4^{19}$.

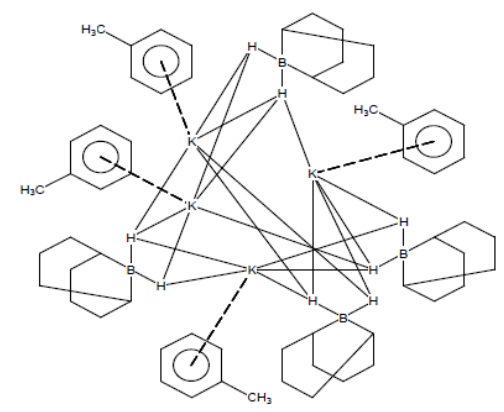

\section{Figure 1.4 Structure of Potassium Dihydroborate and Toluene ${ }^{19}$.}

Seperation of the potassium ion was successful after potassium carbonate was reacted with 2-benzylphenol ${ }^{20}$. The resulting structure [K(2-Benzylphenol $\left.)_{3}\right]$ [2-Benzylphenolate] 
illustrates the interaction of potassium with the phenolic oxygen atom and benzyl ring ${ }^{20}$ (Figure $1.5)$.

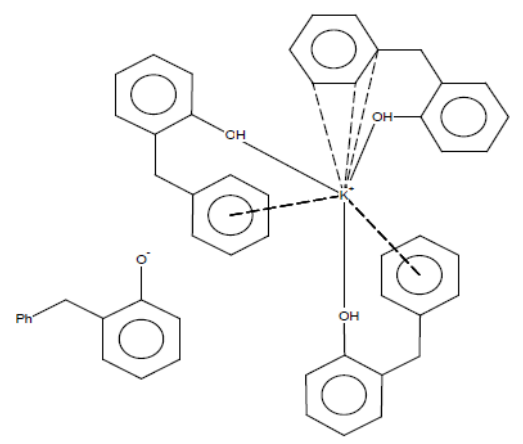

Figure 1.5 [K(2-Benzylphenol $\left.)_{3}\right][2-B e n z y l p h e n o l a t e]$ Structure $^{20}$.

The adduct of 1,3-dimesitylimidazolidin-2-ylidene and 1-chloro-2,3,4,5-

tetraphenylborole was reduced by $\mathrm{KC}_{8} / \mathrm{Et}_{2} \mathrm{O}$ to give, after crystallization, the potassium bridged dimer illustrated in Figure $1.6^{21}$.

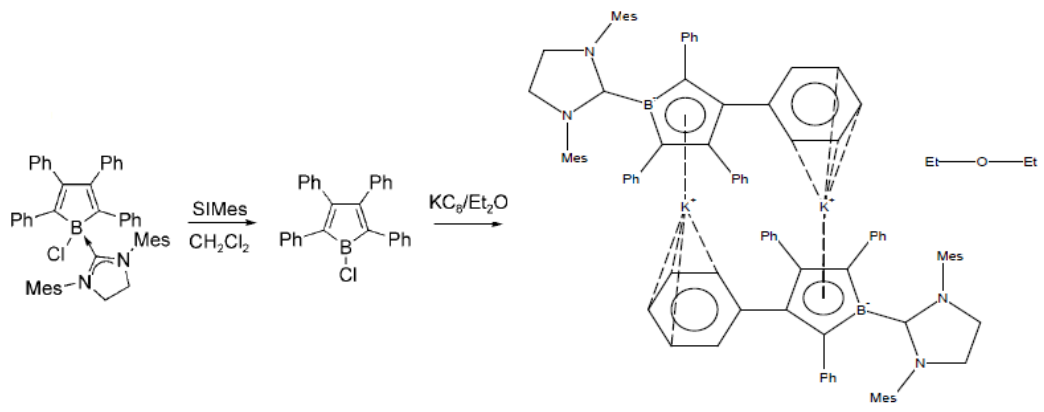

Figure 1.6 Synthesis and Structure of Potassium Bridged Borole Compound ${ }^{21}$.

The goal of this research was to study the reaction of potassium carbanions, such as $\alpha$ cumylpotassium, with epoxides. We began by studying the interaction of potassium with the aromatic rings of cumene and the $\alpha$-cumyl anion (Figure 1.2) through molecular modeling. In order to verify that the interaction of potassium with the aromatic rings of cumene and the $\alpha$ cumyl anion are indeed the reason behind the increased yield observed in Scheme 1.11, cumene was substituted with other aromatic solvents. Finally, non-benzilic organopotassium reagents were reacted with epoxides in order to observe their reactivity and compare their reactivity to that of $\alpha$-cumylpotassium and cyclohexene oxide (Scheme 1.11). 


\section{Chapter 2: Results and Discussion}

\subsection{Molecular Modeling Studies of $\alpha$-Cumylpotassium, Lithium, and Sodium}

The structure of $\alpha$-cumylpotassium and two equivalents of cumene was optimized using the AMPAC 9.1 software package from Semichem Inc. (Figure 2.1). The PM6 model method was required to handle the presence of potassium.

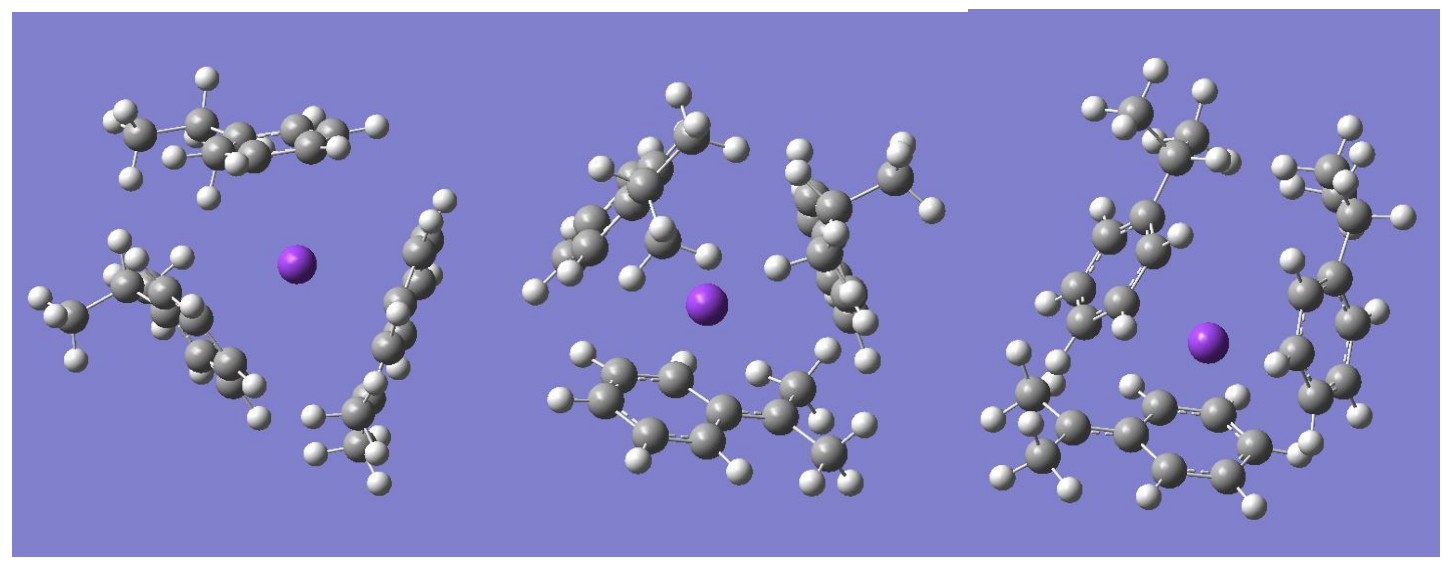

Figure 2.1 Optimization Calculations of $\alpha$-Cumylpotassium and Cumene.

According to the optimized AMPAC model, potassium is centered over the cumyl anion aromatic ring for maximum overlap between carbon Pi orbitals and the potassium $d$-orbitals. This leaves the benzilic position of our $\alpha$-cumyl anion open and flat making it less sterically hindered and a more effective nucleophile. The optimized model also shows coordination of potassium to the aromatic rings of cumene.

Optimization calculations were completed on the structures of $\alpha$-cumyllithium and two equivalents of cumene utilizing AMPAC 9.1 and the parameters described previously. The lithium ion was closer to the benzilic position of the $\alpha$-cumyl anion and seemed to be interacting with the benzilic position and partially with the aromatic ring of one of the cumene equivalents (Figure 2.2). 


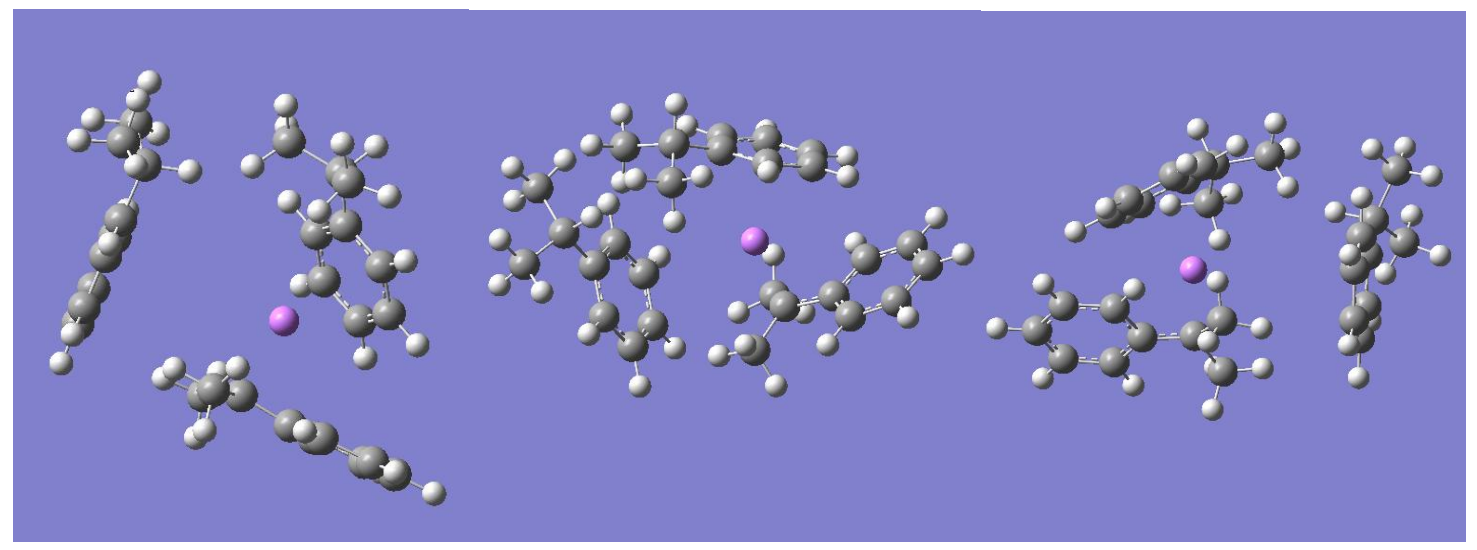

Figure 2.2 Optimization Calculations of $\alpha$-Cumyllithium and Cumene.

The structure of $\alpha$-cumylsodium and two equivalents of cumene was also optimized utilizing AMPAC 9.1 and the same parameters utilized for the potassium and lithium calculations. The interaction between the sodium ion and the benzilic position of the $\alpha$-cumyl anion is stronger than that of the lithium calculations. There also seems to be an interaction between the hydrogens of the methyl of the cumyl anion with the sodium cation (Figure 2.3).

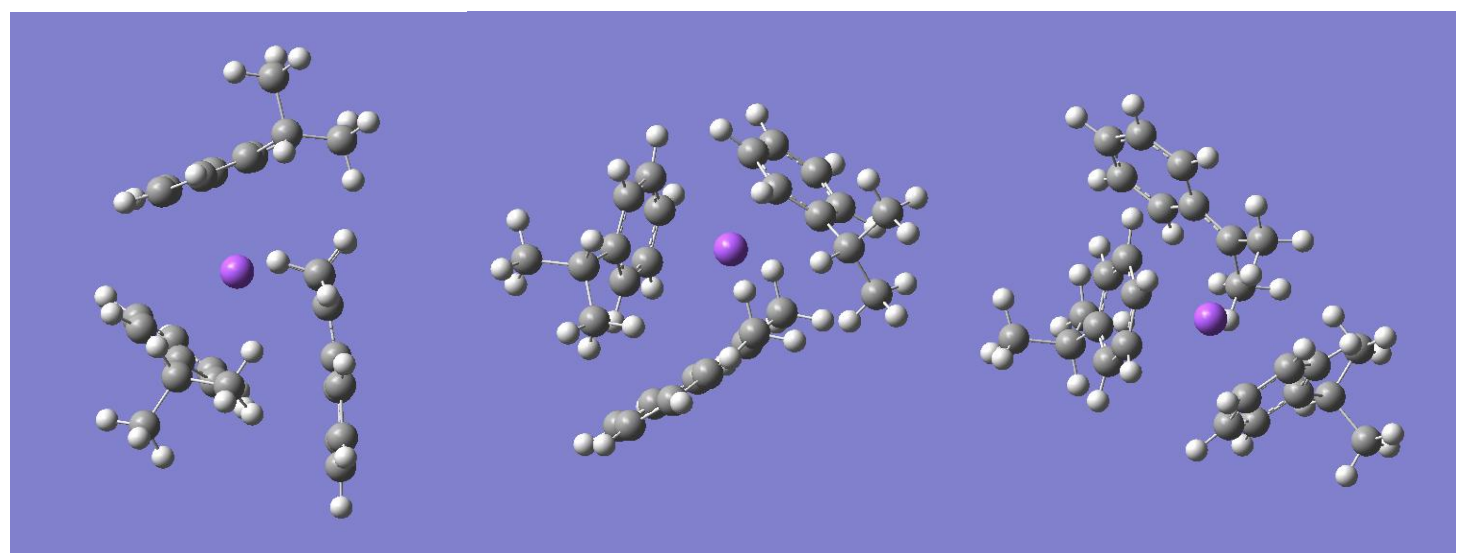

Figure 2.3 Optimization Calculations of $\alpha$-Cumylsodium and Cumene.

The molecular models confirm that $\alpha$-cumylpotassium varies from the other examples because of the $d$-orbital interactions that are only available to potassium but not to lithium or sodium. This is also confirmed from the difficulty in isolating an $\alpha$-cumyl species with lithium ${ }^{22}$ or sodium ${ }^{23}$. 


\subsection{Solvent Effect of Cumene Substitution with Benzene and tert-Butylbenzene}

Observing that the molecular models show an interaction between potassium and the aromatic solvent, we studied the solvent effect on the reaction of $\alpha$-cumylpotassium with cyclohexene oxide. To do this $\alpha$-cumylpotassium was prepared with only one equivalent of cumene and two or more equivalents of different aromatic solvents (Scheme 2.1). The alternative aromatic solvents used were benzene and tert-butylbenzene as outlined below. The yields of the reaction of three equivalents of cumene to using one equivalent of cumene and two or more equivalents of other aromatic solvents were compared.



Scheme 2.1 Substitution of Cumene with Other Aromatic Solvents in the Synthesis of TCC.

\subsubsection{Substitution of Cumene with Benzene}

The first aromatic solvent that was tested was benzene. In this reaction two equivalents of cumene were substituted with three equivalents of benzene (Scheme 2.2) when forming $\alpha$ cumylpotassium, and after two days cyclohexene oxide was added and the reaction was quenched with water. The aqueous layer was extracted with dichloromethane and the combined organic layers were dried over potassium carbonate, filtered, and reduced to give the crude reaction mixture of $1.28 \mathrm{~g}$. A portion of this mixture $(0.600 \mathrm{~g})$ was dissolved in hexanes to give a $5 \mathrm{~mL}$ solution for further analysis.

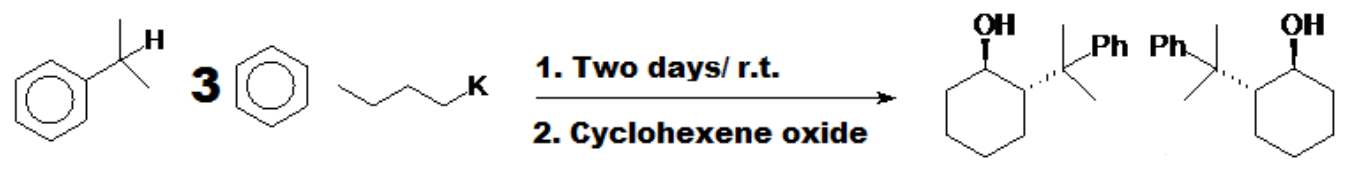

Scheme 2.2 Substitution of Cumene with Benzene in the Synthesis of TCC. 
The amount of TCC present in the crude reaction mixture was determined by Chiral column High Performance Liquid Chromatography (HPLC). An ultraviolet-visible (UV) detector wavelength of $215 \mathrm{~nm}$ was utilized to ensure that the TCC enantiomer peaks were equal. Otherwise overlap with other compounds was observed at the standard $256 \mathrm{~nm}$. The area under the first enantiomer peak of a $3 \mu \mathrm{L}$ sample was compared to the area under the first enantiomer peak of a $1 \mu \mathrm{L}$ sample of a TCC solution of known concentration $(0.122 \mathrm{~g} / 10 \mathrm{~mL}$ hexanes solution). The chromatograms and area data of both solutions are shown in Figures 2.4 and 2.5.

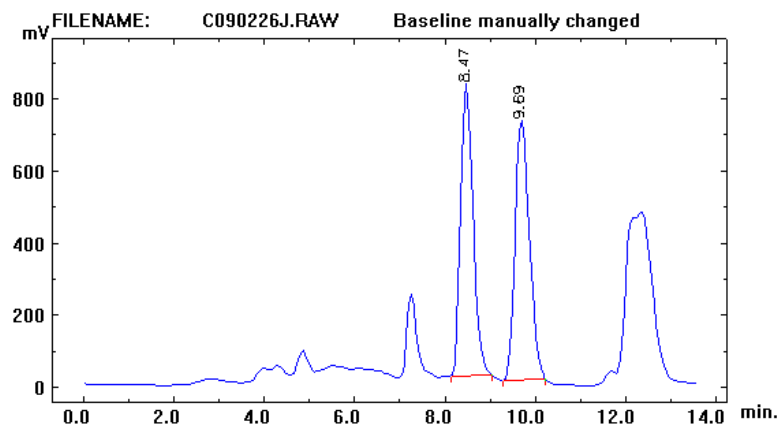

\begin{tabular}{|c|c|c|c|}
\hline Peak \# & AREA \% & RT & AREA \\
\hline 1 & 49.461 & 8.47 & 31457058 \\
\hline 2 & 50.539 & 9.69 & 32142146 \\
\hline
\end{tabular}

Figure 2.4 Chiral HPLC Chromatogram and Data for TCC Synthesis in the Presence of

\section{Benzene.}

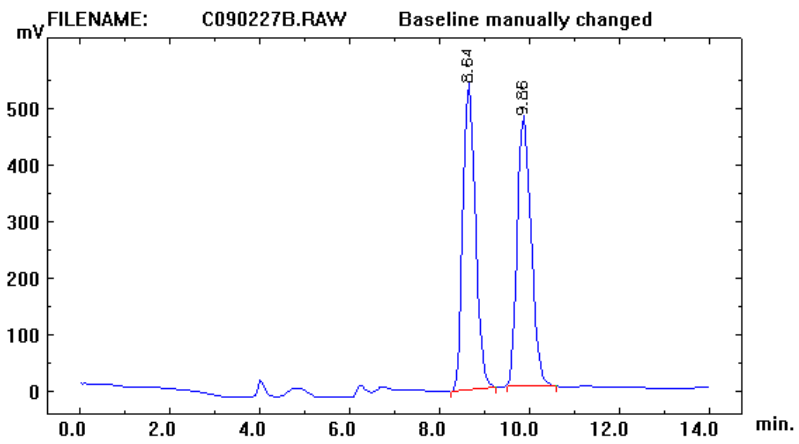

\begin{tabular}{|c|c|c|c|}
\hline Peak \# & AREA \% & RT & AREA \\
\hline 1 & 50.227 & 8.64 & 20794129 \\
\hline 2 & 49.773 & 9.86 & 20605964 \\
\hline
\end{tabular}

Figure 2.5 Chiral HPLC Chromatogram and Data for a TCC Standard Solution.

Once the HPLC results for TCC synthesized with benzene solvent and the standard were obtained, dimensional analysis was utilized to determine that the yield was $3 \%$ given that the theoretical yield was $2.15 \mathrm{~g}$ (Equation 2.1). 


$$
\frac{0.122 \mathrm{~g}}{10 \mathrm{~mL}} \times \frac{1 \mathrm{~mL}}{10^{3} \mu \mathrm{L}} \times \frac{1 \mu \mathrm{L}}{1} \times \frac{31457058}{20794129} \times \frac{5 \mathrm{~mL}}{0.600 \mathrm{~g}} \times \frac{10^{3} \mu \mathrm{L}}{1 \mathrm{~mL}} \times \frac{1}{3 \mu \mathrm{L}} \times \frac{1.28 \mathrm{~g}}{2.15 \mathrm{~g}} \times 100 \%=3 \%
$$

Equation 2.1 Calculation of Percent Yield for TCC Synthesized in the Presence of Benzene.

\subsubsection{Substitution of Cumene with tert-Butylbenzene}

For the reaction with benzene it was noted that a precipitate formed versus the homogenous suspension observed in the reaction when three equivalents of cumene were used. Believing that the difference in the yield of the reactions was due to solubility, tert-butylbenzene was tested. Two equivalents of tert-butylbenzene were used in the same reaction sequence as previously described for benzene (Scheme 2.3). HPLC analysis was performed on $3 \mu \mathrm{L}$ of a crude reaction sample solution of $0.134 \mathrm{~g}$ in $10 \mathrm{~mL}$ of hexanes (Figure 2.6) and the percent yield was determined to be $27 \%$ (Equation 2.2).

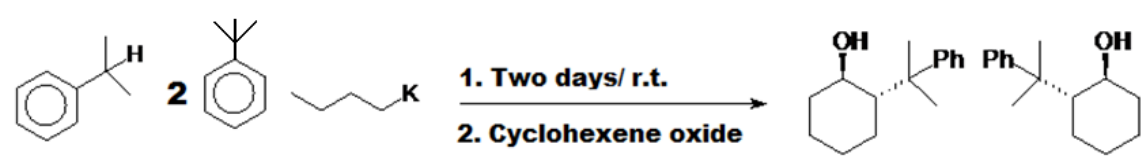

Scheme 2.3 Substitution of Cumene with tert-Butylbenzene in the Synthesis of TCC.

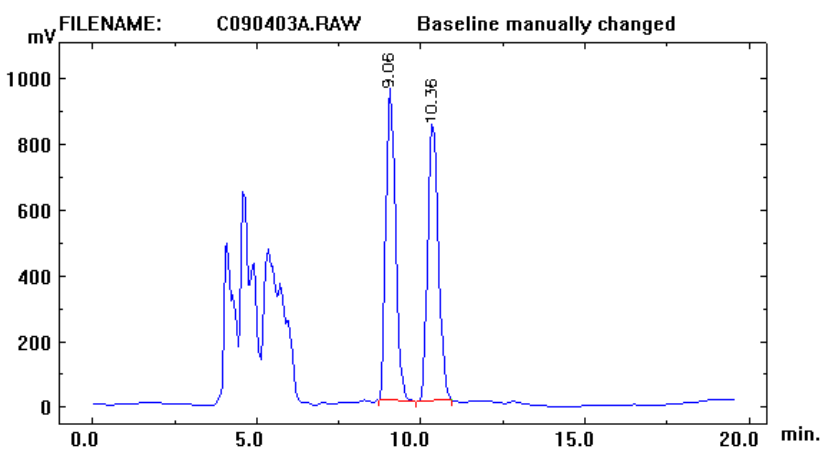

\begin{tabular}{|c|c|c|c|}
\hline Peak\# & AREA $\%$ & RT & AREA \\
\hline 1 & 50.083 & 9.06 & 38571826 \\
\hline 2 & 49.917 & 10.36 & 38444028 \\
\hline
\end{tabular}

Figure 2.6 Chiral HPLC Chromatogram and Data for TCC Synthesis in the Presence of tert-Butylbenzene. 


$$
\frac{0.122 \mathrm{~g}}{10 \mathrm{~mL}} \times \frac{1 \mathrm{~mL}}{10^{3} \mu \mathrm{L}} \times \frac{1 \mu \mathrm{L}}{1} \times \frac{38571826}{20794129} \times \frac{10 \mathrm{~mL}}{0.134 \mathrm{~g}} \times \frac{10^{3} \mu \mathrm{L}}{1 \mathrm{~mL}} \times \frac{1}{3 \mu \mathrm{L}} \times \frac{1.024 \mathrm{~g}}{2.15 \mathrm{~g}} \times 100=27 \%
$$

\section{Equation 2.2 Calculation of Percent Yield for TCC Synthesized in the Presence of tert- \\ Butylbenzene.}

\subsection{Kinetic Studies on the Reaction of $\alpha$-Cumylpotassium with Cyclohexene Oxide}

The increased yield was consistent with the observation that the tert-butylbenzene reaction was more homogeneous than the benzene reaction, but the yields for both reactions were much lower than that of the original reaction. At this point we began to question the validity of our original hypothesis that predicted the formation of a complex with the $\alpha$-cumyl anion and the aromatic solvent (Figure 1.2). We realized that if we needed three equivalents of cumene to form the hypothesized complex: One to form the $\alpha$-cumyl anion and two others to interact with the potassium ion then a reaction in which one equivalent of cumene was utilized could never produce more than a 30\% yield. Regardless of how long the reaction was allowed to run, an experiment in which two equivalents of cumene were utilized would never exceed a $60 \%$ yield. On the contrary, if the yield exceeded $30 \%$ for a one equivalent reaction and $60 \%$ for a two equivalent experiment over a period of time then we would prove that the reaction yield is an issue of kinetics and not the amount of aromatic solvent present.

\subsubsection{Production of trans-Cumylcyclohexanol in the Presence of 1.1 Equivalents of}

\section{Cumene}

We predicted that the increase in yield was due to the rate of the reaction of $n$ butylpotassium and cumene to produce $\alpha$-cumylpotassium (Scheme 1.10). Our goal was to determine if the overall yield of the reaction would increase over time if the amount of cumene 
was kept constant. In order to accomplish this goal, a series of reactions were set up simultaneously in which the amount of cumene utilized was 1.1 equivalents and all the other reagents were kept constant. The only difference was the amount of time allowed prior to adding cyclohexene oxide to the reaction (Scheme 2.4 and Table 2.1).
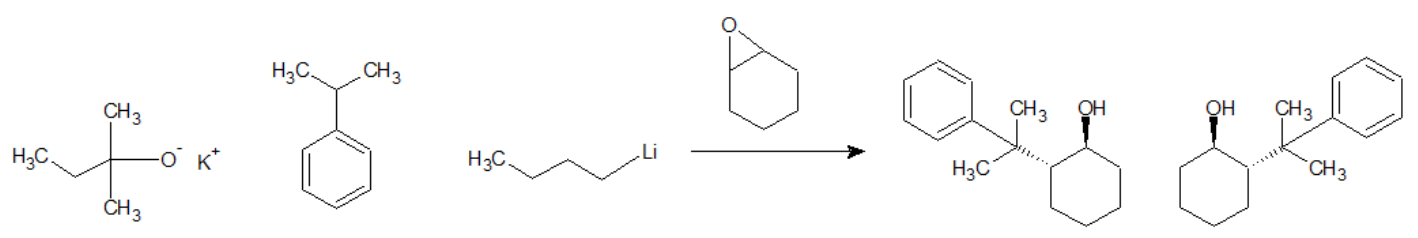

Scheme 2.4 Reaction Scheme for Kinetic Experiments.

Table 2.1 1.1 Equivalents of Cumene, Kinetic Experiment Conditions and Results.

\begin{tabular}{|c|c|c|c|c|c|c|}
\hline Flask & Potassium tert-Amylate & Cumene & $n$-Butyllithium & Time & Cyclohexene & Yield \\
(Days) & Oxide & $(\%)$ \\
\hline 1 & $1.2 \mathrm{eq}$ & $\mathbf{1 . 1} \mathbf{~ e q}$ & 1 eq & $\mathbf{2}$ & 1 eq & $\mathbf{4 9}$ \\
\hline 2 & $1.2 \mathrm{eq}$ & $\mathbf{1 . 1} \mathbf{~ e q}$ & 1 eq & $\mathbf{4}$ & 1 eq & $\mathbf{6 7}$ \\
\hline 3 & $1.2 \mathrm{eq}$ & $\mathbf{1 . 1} \mathbf{~ e q}$ & $1 \mathrm{eq}$ & $\mathbf{6}$ & 1 eq & $\mathbf{6 8}$ \\
\hline 4 & $1.2 \mathrm{eq}$ & $\mathbf{1 . 1} \mathbf{~ e q}$ & $1 \mathrm{eq}$ & $\mathbf{8}$ & 1 eq & $\mathbf{7 4}$ \\
\hline 5 & $1.2 \mathrm{eq}$ & $\mathbf{1 . 1} \mathbf{~ e q}$ & $1 \mathrm{eq}$ & $\mathbf{1 0}$ & 1 eq & $\mathbf{6 7}$ \\
\hline
\end{tabular}

The reason behind utilizing 1.1 equivalents of cumene and not 1 equivalent of cumene lies in previous work done by Benkeeser. As mentioned previously, the reaction of $n$ butylpotassium with cumene to produce $\alpha$-cumylpotassium takes two days (Scheme 1.10$)^{17}$. This is because deprotonation occurs first on the aromatic ring of cumene, particularly at the meta and para positions and it is only after two days that the thermodynamically favored product, which 
requires deprotonation at the benzillic position, can be obtained in the presence of excess cumene (Scheme 2.5) ${ }^{17}$. In other words, without excess cumene no equilibration between ring and benzilic anions is possible.

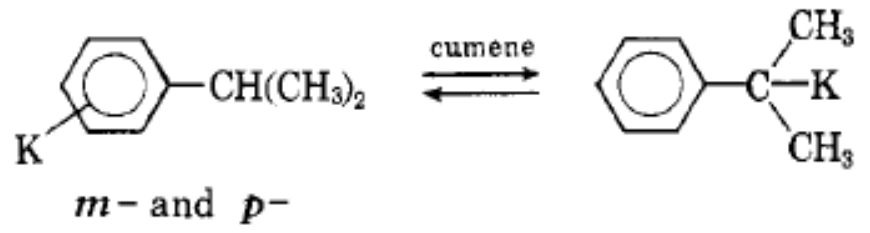

Scheme 2.5 Equilibrium of meta and para Metalated Cumene and the Thermodynamically Favored $\alpha$-Cumylpotassium?.

\subsubsection{Production of trans-Cumylcyclohexanol in the Presence of 2.0 Equivalents of}

\section{Cumene}

After two days the yield of the 1.1 equivalent reaction was $49 \%$ and after eight days a yield of $74 \%$ was achieved. It was then determined that a second set of reactions should be carried out in which 2 equivalents of cumene were utilized (Table 2.2).

The yield for the two equivalent reaction was determined after one day because it was unclear as to how much of an effect the extra cumene would have on the rate of the reaction. The yield after one day was $65 \%$ and after eight days the yield reached a high of $72 \%$. A plot of the yields for both the 1.1 and 2 equivalent experiments is shown in Figure 2.7. 
Table 2.2 2.0 Equivalents of Cumene, Kinetic Experiment Conditions and Results.

\begin{tabular}{|c|c|c|c|c|c|c|}
\hline Flask & Potassium tert-Amylate & Cumene & $n$-Butyllithium & $\begin{array}{l}\text { Time } \\
\text { (Days) }\end{array}$ & $\begin{array}{c}\text { Cyclohexene } \\
\text { Oxide }\end{array}$ & $\begin{array}{c}\text { Yield } \\
(\%)\end{array}$ \\
\hline 1 & $1.2 \mathrm{eq}$ & $2 \mathrm{eq}$ & 1eq & 1 & 1eq & 65 \\
\hline 2 & $1.2 \mathrm{eq}$ & $2 \mathrm{eq}$ & $1 \mathrm{eq}$ & 2 & $1 \mathrm{eq}$ & 71 \\
\hline 3 & $1.2 \mathrm{eq}$ & $2 \mathrm{eq}$ & $1 \mathrm{eq}$ & 4 & 1 eq & 71 \\
\hline 4 & $1.2 \mathrm{eq}$ & $2 \mathrm{eq}$ & 1eq & 6 & leq & 69 \\
\hline 5 & $1.2 \mathrm{eq}$ & $2 \mathrm{eq}$ & leq & 8 & leq & 72 \\
\hline 6 & $1.2 \mathrm{eq}$ & 2 eq & 1eq & 10 & leq & 58 \\
\hline
\end{tabular}

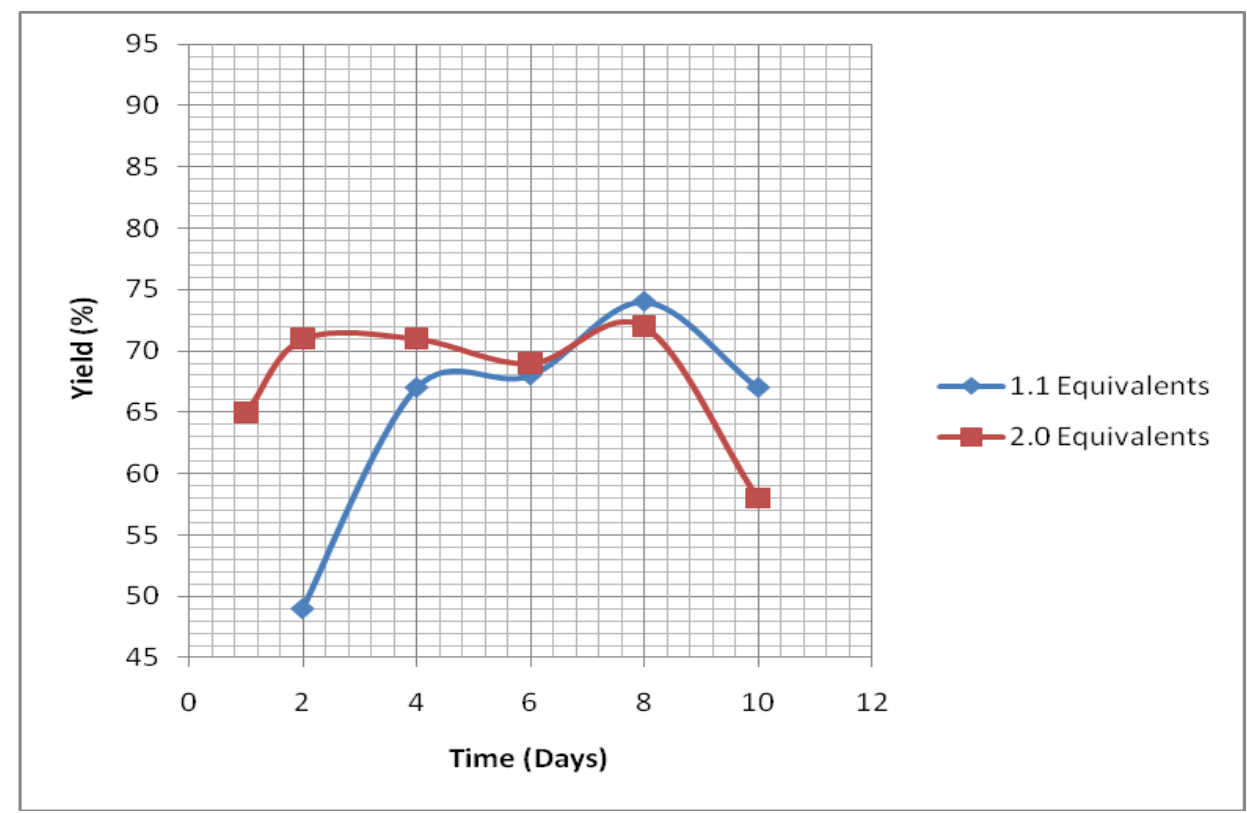

Figure 2.7 Time vs. Percent Yield of the 1.1 and 2.0 Equivalents of Cumene Reactions.

It was noted that for both the 1.1 and 2 equivalent reactions there was a significant decrease in yield after day eight. This was attributed to evaporation of cumene and its absorption 
into the septum as well as the inability to exclude air and water from the anhydrous environment for extended periods of time. It is also possible that the decrease was due to other reactions that can occur over prolonged periods of time as observed for $\alpha$-cumyllithium ${ }^{22}$ and sodium ${ }^{23}$ reagents.

\subsection{Reactivity of Other Organopotassium Species}

After studying the $\alpha$-cumylpotassium reaction extensively, our attention was turned to other examples of organopotassium species that are not benzilic because it was demonstrated that an aromatic solvent is not necessary to carry out the ring opening reactions of potassium anions with epoxides.

\subsubsection{Reaction of $n$-Butylpotassium and Cyclohexene Oxide}

We decided to investigate the reaction of $n$-butylpotassium with cyclohexene oxide (Scheme 2.6) and compare its reactivity to that of the tertiary benzilic organopotassium species, $\alpha$-cumylpotassium. We chose to study $n$-butylpotassium because it is a primary organopotassium species that was readily available to us through the potassium-lithium ion exchange reaction of potassium tert-amylate and $n$-butyllithium (Scheme 1.9).

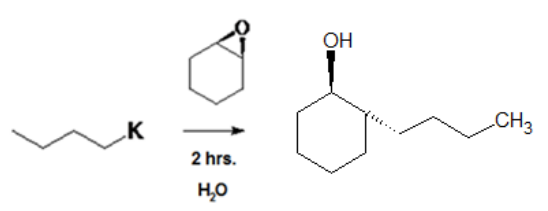

\section{Scheme 2.6 Reaction of $\boldsymbol{n}$-Butylpotassium and Cyclohexene Oxide.}

$\alpha$-Cumylpotassium, a tertirary organopotassium species, attacks cyclohexene oxide at its secondary position through a substitution mechanism to produce trans-cumylcyclohexanol. It was predicted that in the case of the primary organopotassium species, $n$-butylpotassium, that 
substitution would also lead to the production of trans-2-butylcyclohexan-1-ol (Scheme 2.6). Carbon 13 Nuclear Magnetic Resonance $\left({ }^{13} \mathrm{C}\right.$ NMR) of the product mixture did not give any indication of the production of an alcohol but there was indication of the presence of a carbonyl group at a chemical shift of 213.7 ppm (Figure 2.8). Proton NMR $\left({ }^{1} \mathrm{H}\right.$ NMR) and Distortionless Enhancement by Polarization Transfer- $135^{\circ}$ (DEPT-135) were conducted on the sample to ensure that an alcohol had not been produced (Figures 2.9 and 2.10).

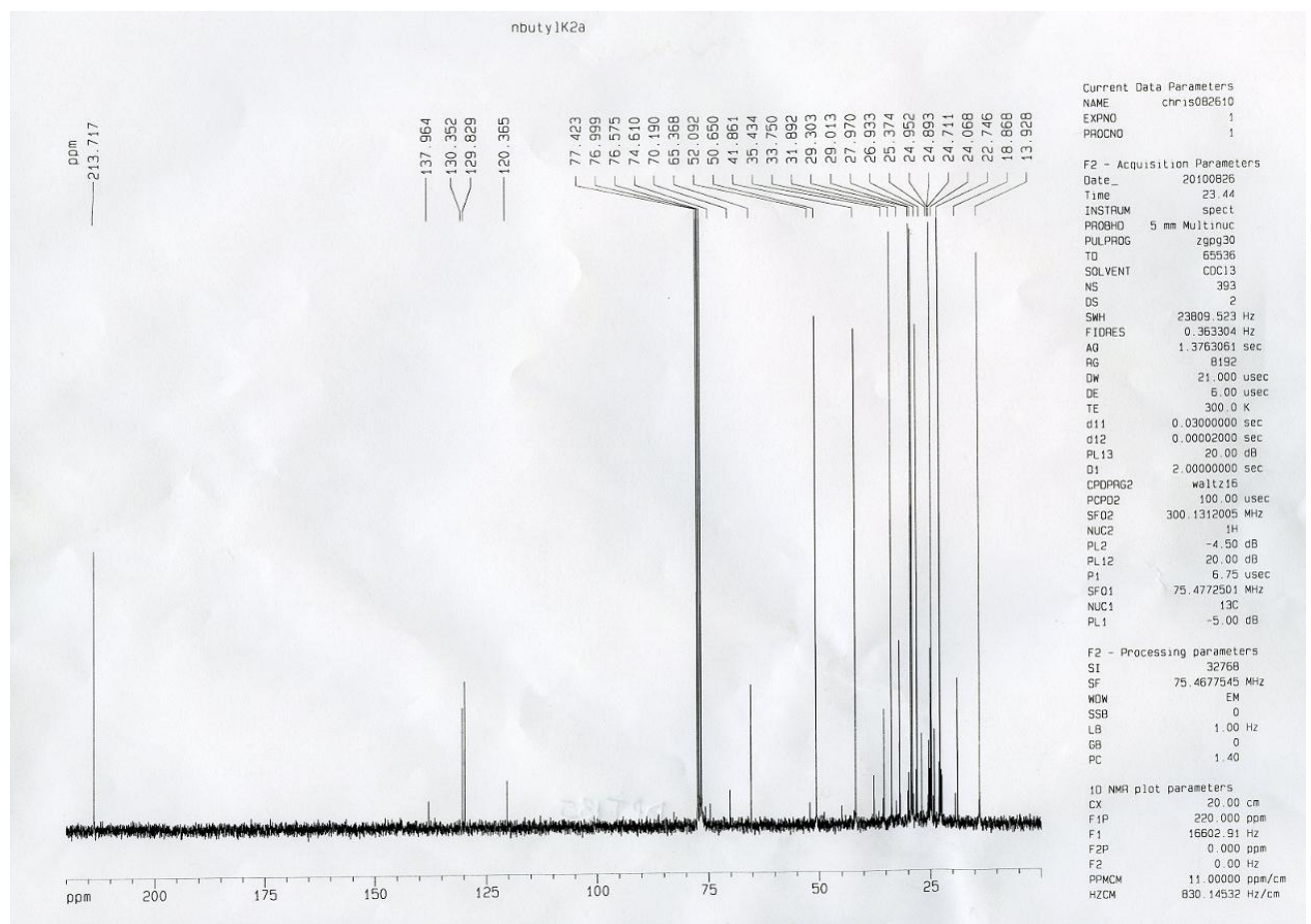

Figure 2.8 ${ }^{13} \mathrm{C}$ NMR Spectrum of Crude Product from the Reaction of $\boldsymbol{n}$-Butylpotassium and Cyclohexene Oxide. 


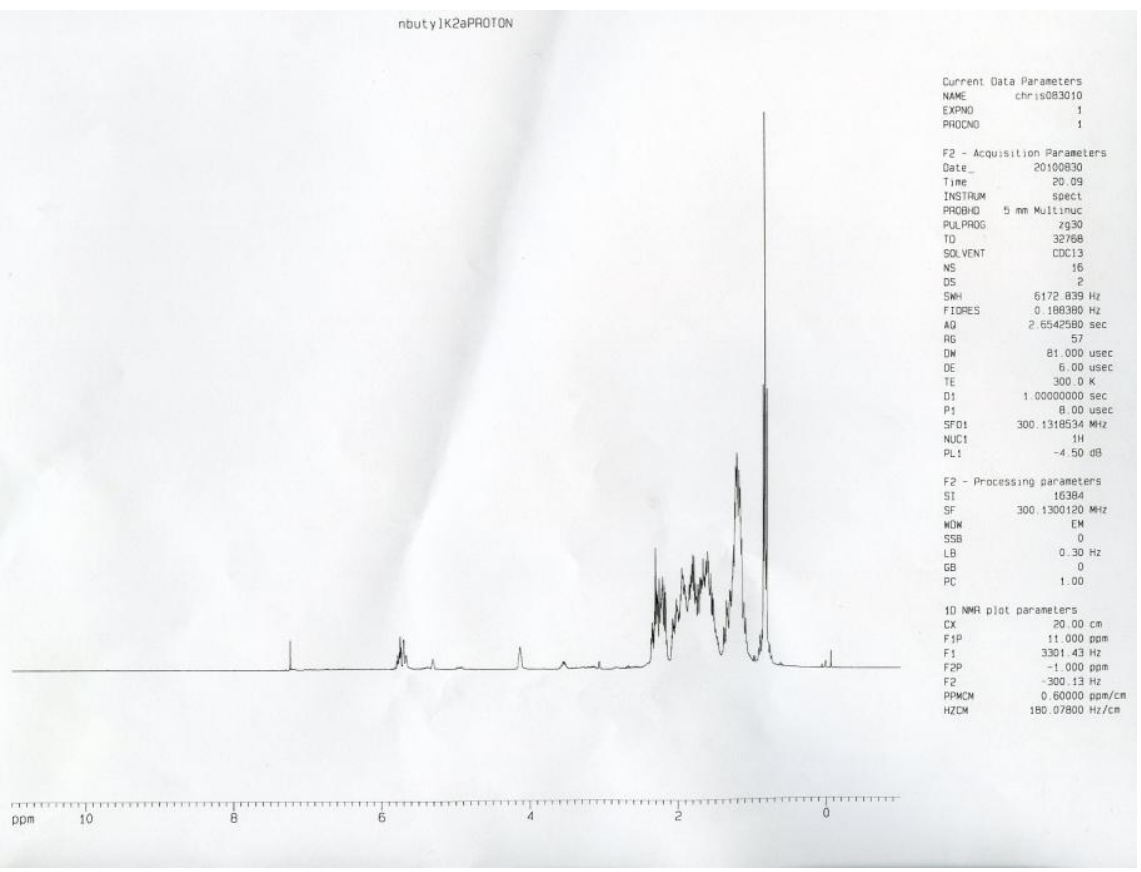

Figure 2.9 ${ }^{1} \mathrm{H}$ NMR Spectrum of Crude Product from the Reaction of $\boldsymbol{n}$-Butylpotassium and Cyclohexene Oxide.

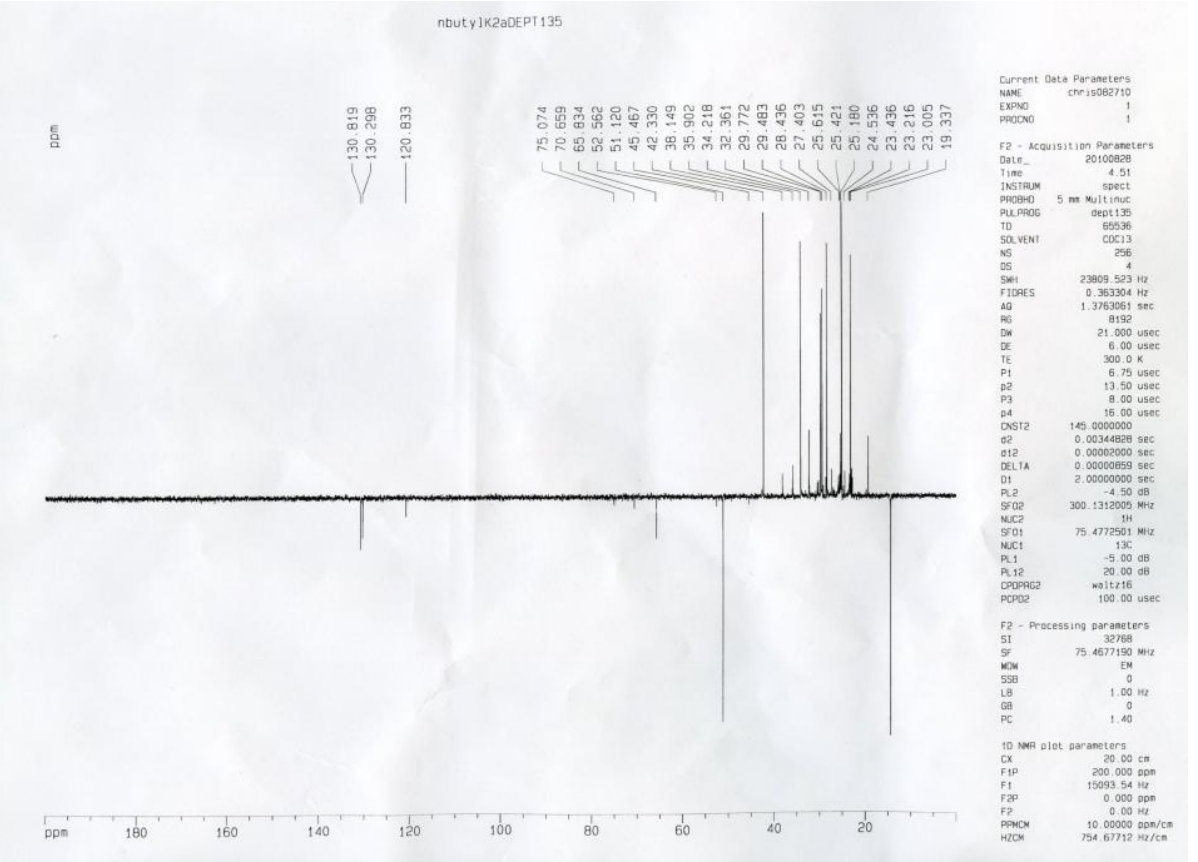

Figure 2.10 DEPT-135 Spectrum of Crude Product from the Reaction of $n$-Butylpotassium and Cyclohexene Oxide. 


\subsubsection{Reaction of $n$-Butyllithium and Cyclohexene Oxide}

In order to verify that we were obtaining a unique result we compared the product of the $n$-butylpotassium reaction (Scheme 2.6) with the reaction of $n$-butyllithium with cyclohexene oxide (Scheme 1.2). The reaction of $n$-butyllithium with cyclohexene oxide has been studied and is known to produce cyclohex-2-en-1-ol ${ }^{6}$. We ran the reaction of $n$-butyllithium with cyclohexene oxide under the same conditions of the $n$-butylpotassium reaction and obtained a ${ }^{13} \mathrm{C}$ NMR spectrum for the reaction product (Figure 2.11 ). The peak at $74.5 \mathrm{ppm}$ is characteristic of the alcohol functionality associated with the elimination product cyclohexenol. We also observe the pair of peaks at 129.8 and $130.1 \mathrm{ppm}$ which correspond to the unsaturated carbons of the cyclohexenol. We also see a small peak at $212.3 \mathrm{ppm}$, but it is not the same value as the peak found in the $n$-butylpotassium reaction ${ }^{13} \mathrm{C}$ NMR nor does it have the same intensity (Figure 2.8).

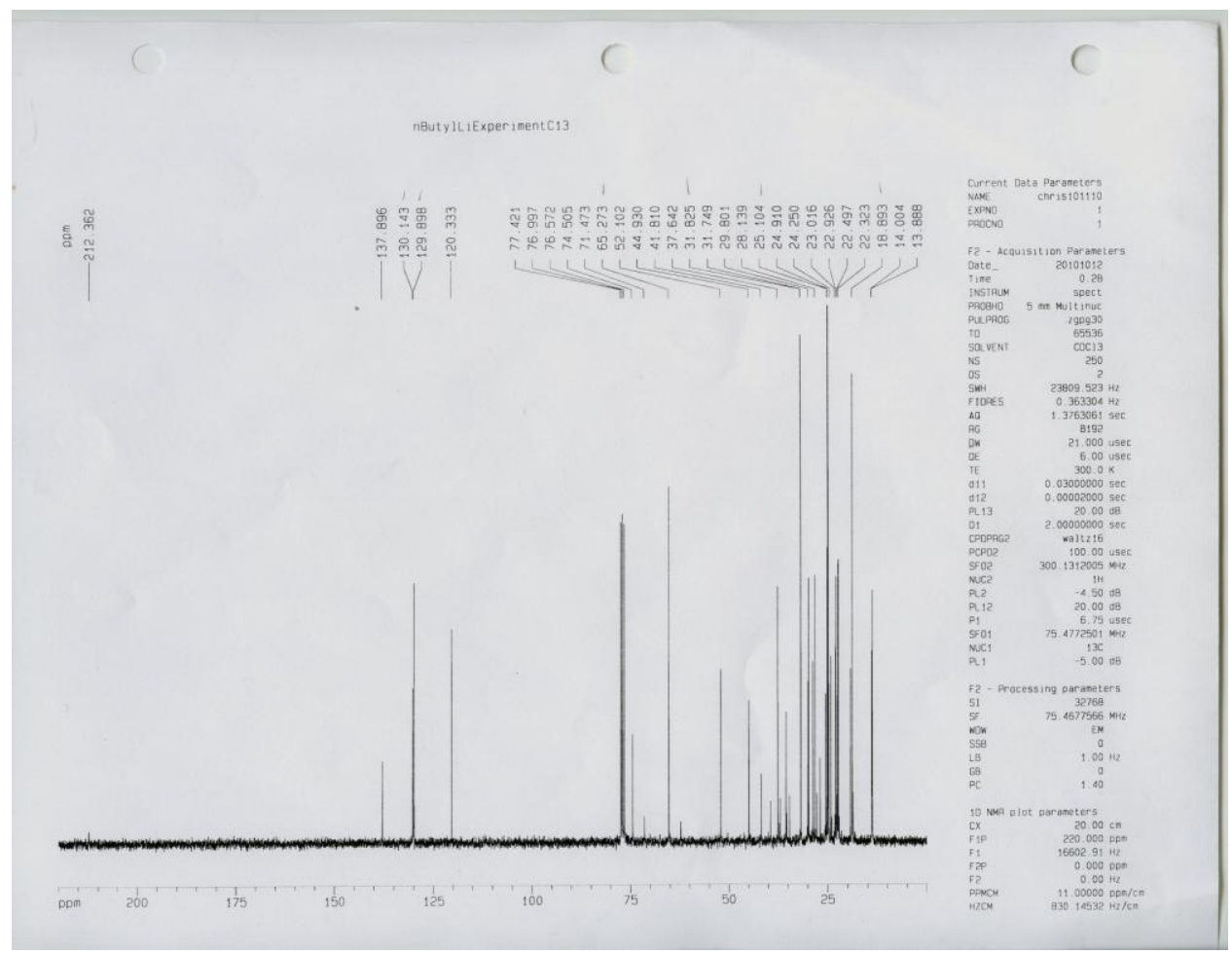

Figure 2.11 ${ }^{13}$ C NMR of Crude Product from the Reaction of $n$-Butyllithium with Cyclohexene Oxide. 
The ${ }^{13} \mathrm{C}$ NMR spectra clearly indicate that the reaction of $n$-butyllithium with cyclohexene oxide does not produce the same products as the reaction of $n$-butylpotassium with cyclohexene oxide.

\subsubsection{Isolation and Analysis of 2-Butylcyclohexanone}

Once this had been determined we continued by trying to isolate the product associated with the carbonyl peak from the ${ }^{13} \mathrm{C}$ NMR of the $n$-butylpotassium reaction with cyclohexene oxide (Scheme 2.6). We accomplished this by utilizing radial chromatography on a portion of the reaction sample. We then took the ${ }^{13} \mathrm{C}$ NMR of the first fraction that eluded from the Chromatotron (Figure 2.12).

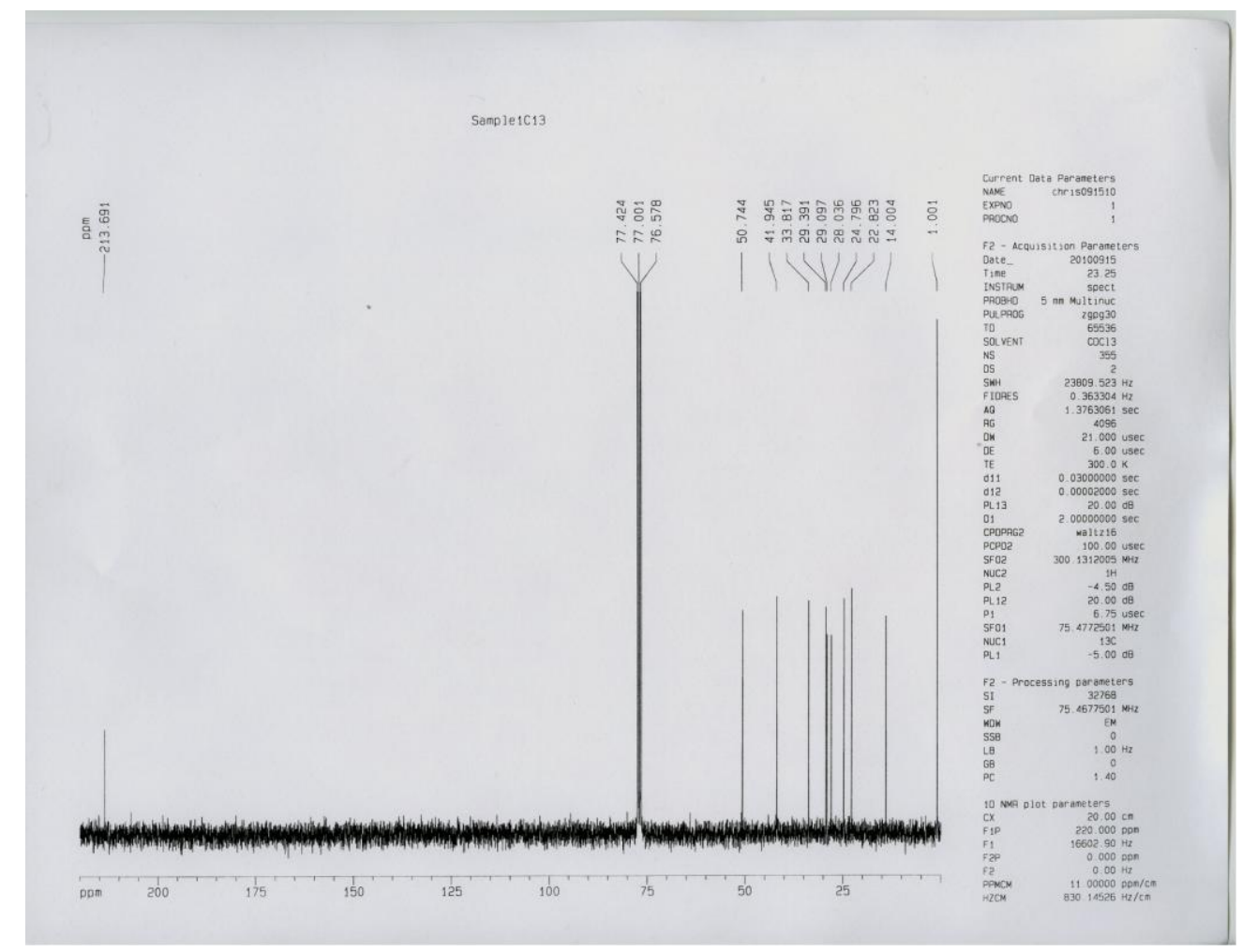

Figure $2.12{ }^{13} \mathrm{C}$ NMR Spectrum of First Fraction Isolated by Radial Chromatography. 
The ${ }^{13} \mathrm{C}$ NMR shows nine peaks from 14.0 to $50.7 \mathrm{ppm}$ and one peak at $213.6 \mathrm{ppm}$ that corresponds to a carbonyl carbon. The ${ }^{13} \mathrm{C}$ NMR led us to conclude that the six carbon cyclohexene oxide and the four carbon $n$-butylpotassium had come together in the reaction to produce 2-butylcyclohexanone in a $2 \%$ isolated yield (Scheme 2.7). The identity of the compound was confirmed by a comparison to the literature ${ }^{24}$.

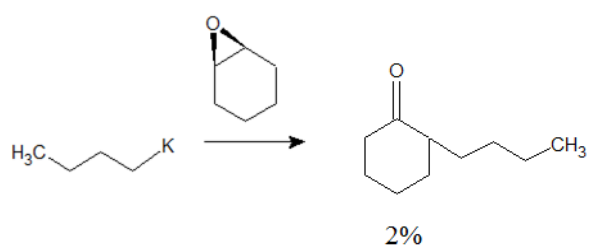

Scheme 2.7 Reaction of $\boldsymbol{n}$-Butylpotassium and Cyclohexene Oxide to Produce 2-

Butylcyclohexanone.

Prior to isolation through chromatography, a mass spectrum was obtained for the crude reaction sample (Figure 2.13). The peak at $155.1430(\mathrm{~m} / \mathrm{z})$ corresponds to the calculated mass of 2-butylcyclohexanone $[\mathrm{M}+\mathrm{H}]_{\mathrm{cal}}=155.14359$ as well as the mass reported in the literature ${ }^{24}$.

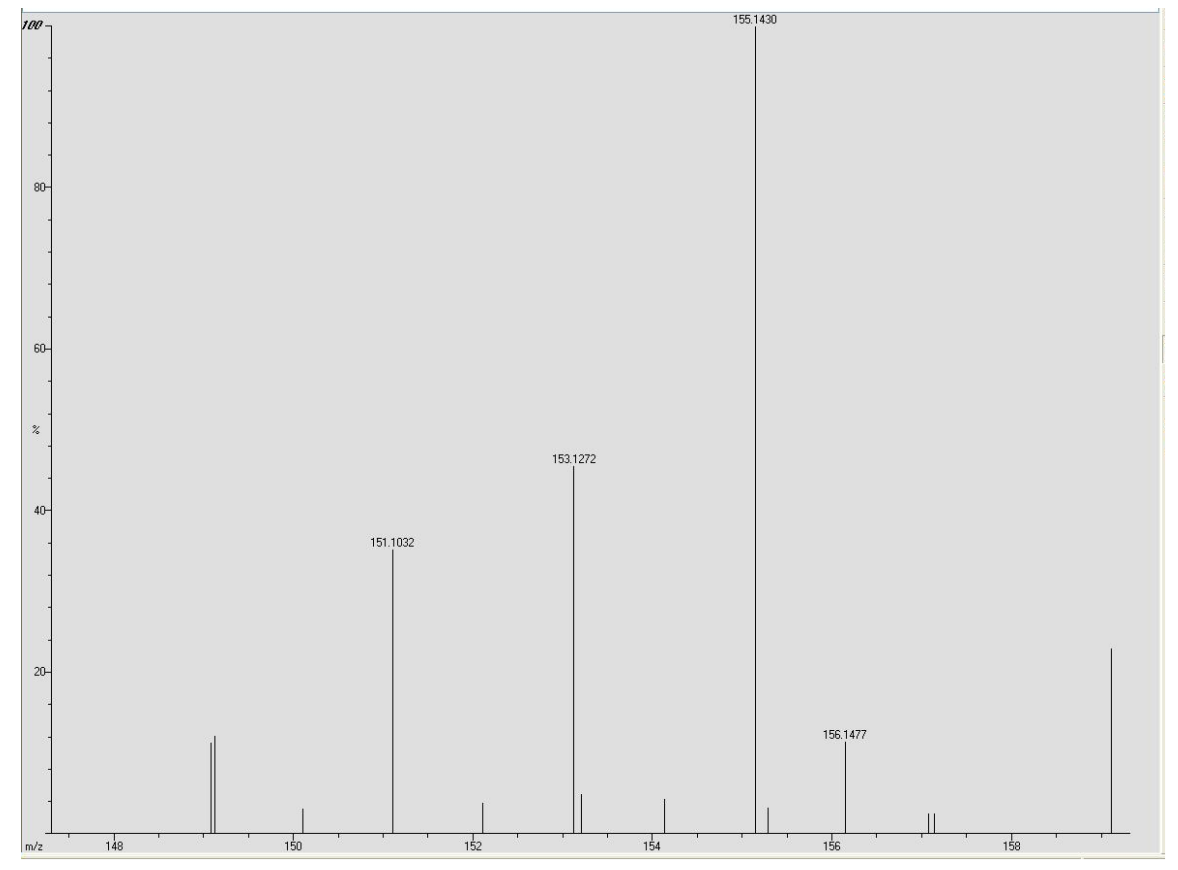

Figure 2.13 Mass Spectrum with Parent Peak for 2-Butylcyclohexanone. 


\subsubsection{Derivatization of 2-Butylcyclohexanone}

In an attempt to further verify our product and increase the isolated yield of the reaction, semicarbazide was added to the crude reaction mixture before evaporation of solvents to give the corresponding semicarbazone in an isolated yield of $10 \%$ after recrystallization (Scheme 2.8). The product was then analyzed by ${ }^{13} \mathrm{C}$ NMR (Figure 2.14). The improved isolated yield of the semicarbazone versus underivatized compound may be a consequence of the volatility of 2butylcyclohexanone as apparent by its spearmint like aroma.

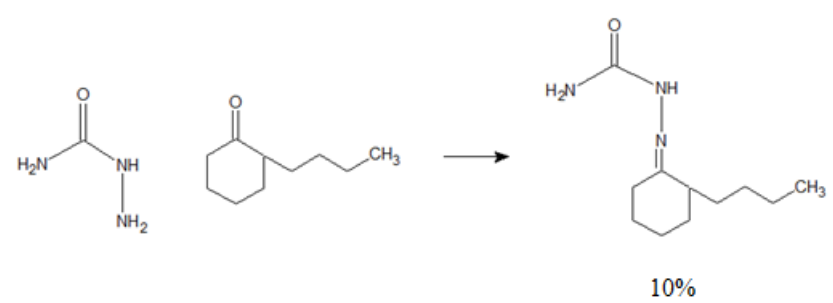

\section{Scheme 2.8 Reaction of 2-Butylcyclohexanone with Semicarbazide to Produce 2-}

\section{Butylcyclohexanone Semicarbazone.}

The ${ }^{13} \mathrm{C}$ NMR of the 2-butylcyclohexanone semicarbazone was calculated using the ${ }^{13} \mathrm{C}$ NMR Predictor Software from ACD Labs (Figure 2.15) and matched the ${ }^{13} \mathrm{C}$ NMR of the recrystallized semicarbazone (Figure 2.14). The melting point of the 2-butylcyclohexanone semicarbazone recrystallized in ethanol was $134^{\circ} \mathrm{C}$. Melting points for 2-butylcyclohexanone semicarbazone have been published that range from $138.5^{\circ}-150^{\circ} \mathrm{C}^{25-28}$. 


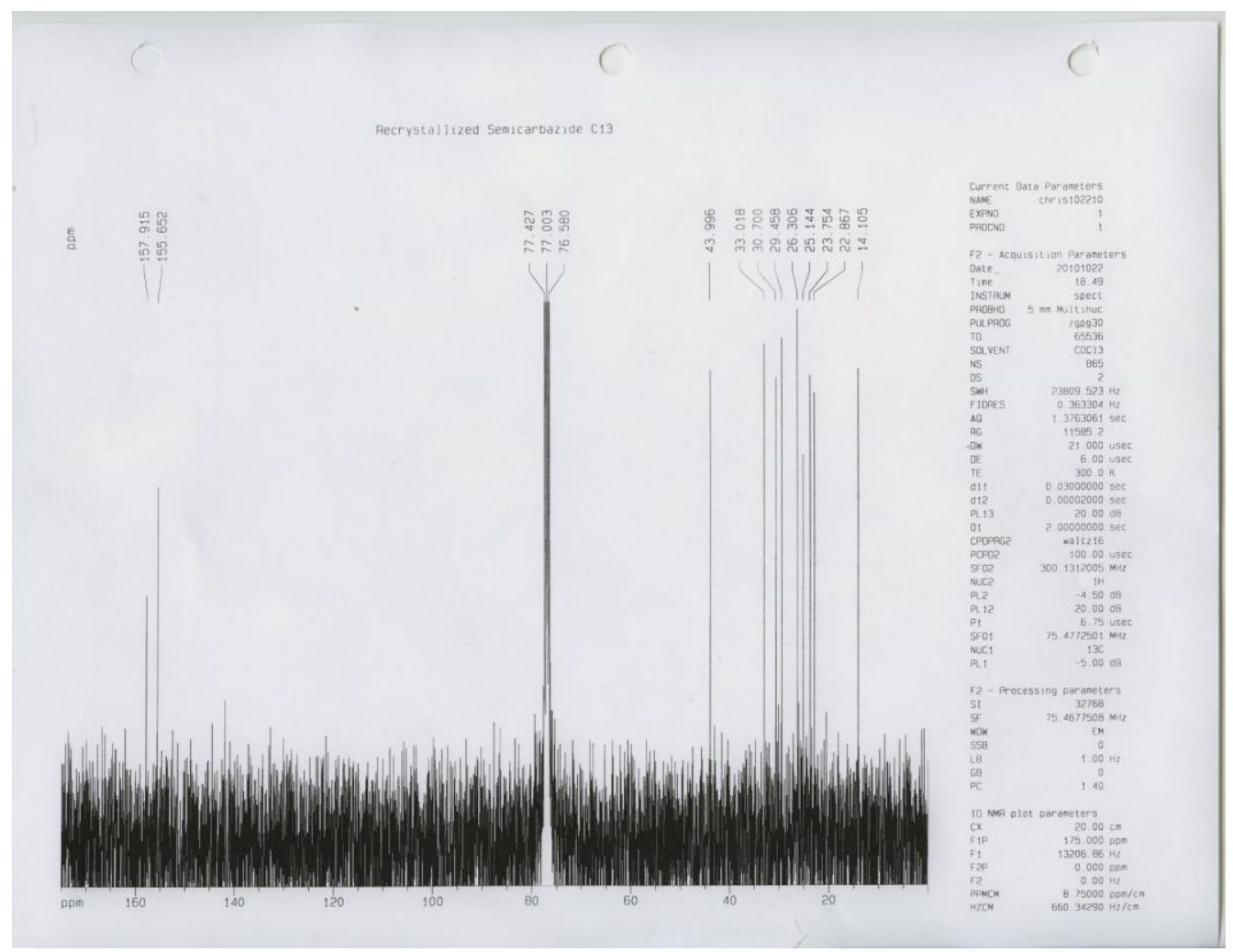

Figure 2.14 ${ }^{13} \mathrm{C}$ NMR of 2-Butylcyclohexanone Semicarbazone.

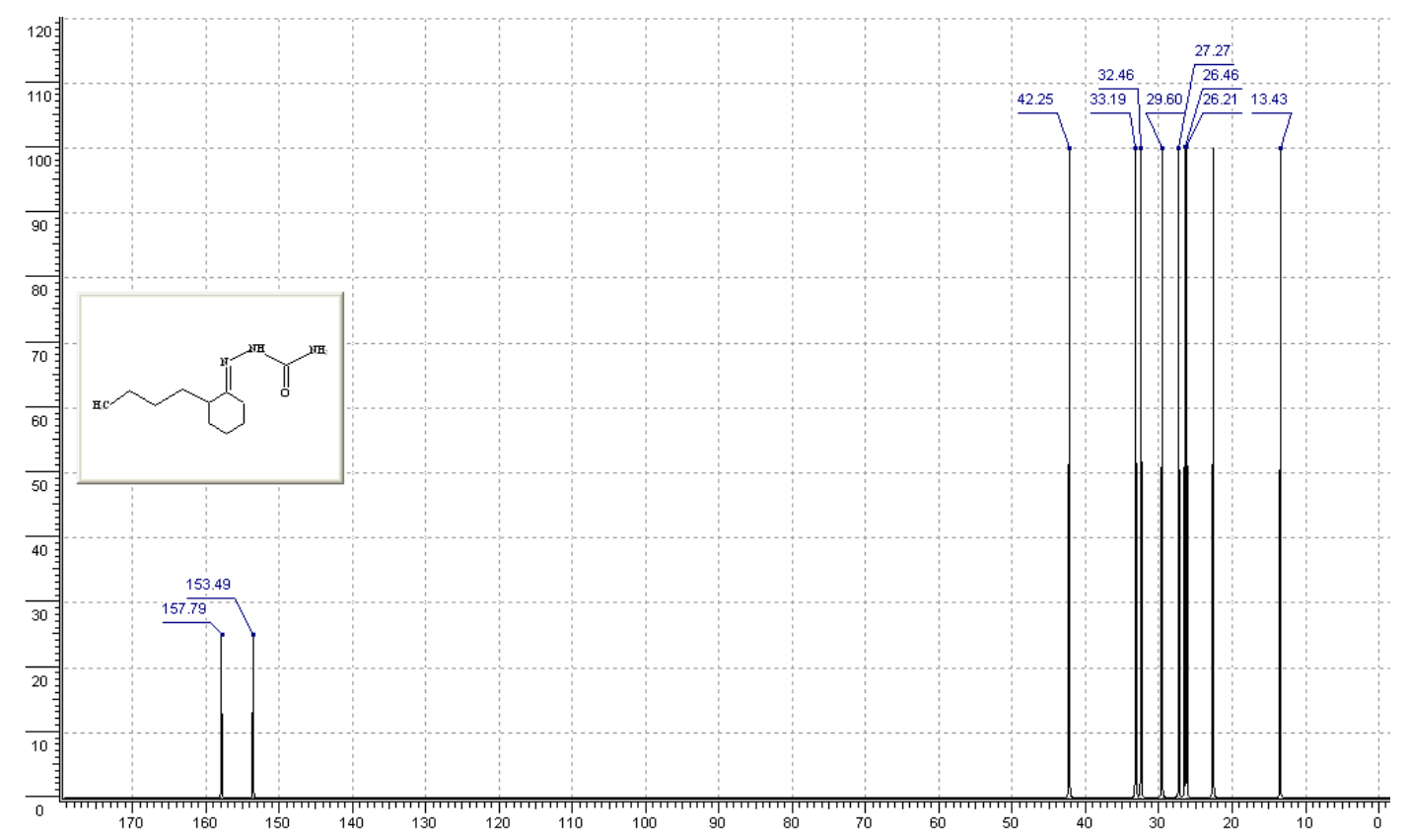

Figure 2.15 Calculated ${ }^{13} \mathrm{C}$ NMR for 2-Butylcyclohexanone Semicarbazone. 


\subsubsection{Hypothetical Mechanism for Formation of 2-Butylcyclohexanone}

Once the identity of our product had been verified to be 2-butylcyclohexanone, a hypothesis on the mechanism of the reaction could be made. Prior to this, we first analyzed the potassium reagent of our reaction to verify that there were no other metals present in the reaction that could be causing some type of oxidation or dehydrogenation because 2-butylcyclohexanone is an oxidized form of our predicted product, trans-2-butylcyclohexan-1-ol. We analyzed our potassium reagent, potassium tert-amylate, by X-ray Fluorescence (Figure 2.16).

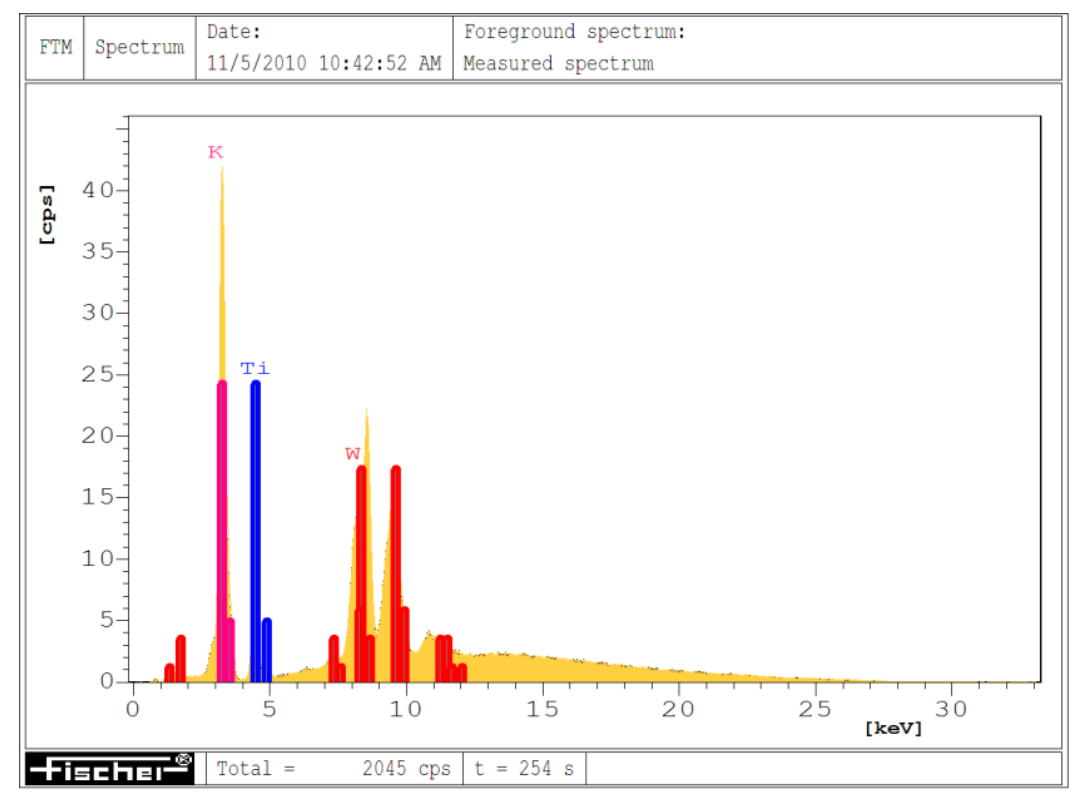

Figure 2.16 X-Ray Fluorescence of Potassium tert-Amylate.

The X-ray fluorescence shows a peak for titanium that comes from the stage of the instrument, tungsten that is associated with the source and finally potassium that is in our reagent. We concluded that our sample did not have any other metals present at the level of detection.

Once the purity of our potassium reagent had been verified we continued with the determination of the mechanism that led to the production of the 2-butylcyclohexanone from the reaction of $n$-butylpotassium and cyclohexene oxide. A review of the literature led us to 
postulate the following three step mechanism. First, the work done by Hodgson et. al. describes that in the presence of a strong base epoxides can rearrange to enolates through a carbene intermediate $^{29}($ Scheme 2.9$)$.

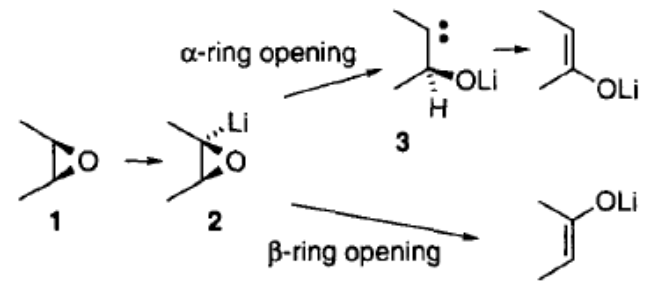

\section{Scheme 2.9 Rearrangement of Epoxides to Enolates Through a Carbene Intermediate ${ }^{29}$.}

Second, work conducted by Oku et. al. describes that ketones can be produced when carbenes react with secondary alkoxides by hydride abstraction to produce ketones ${ }^{30}\left(\right.$ Scheme $^{2}$ 2.10).

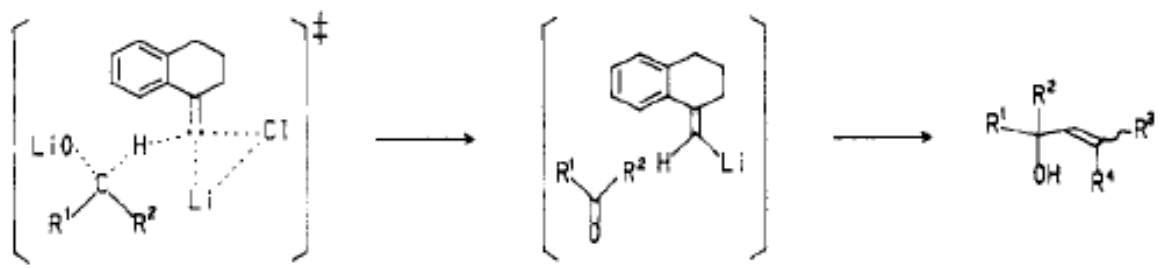

\section{Scheme 2.10 Reaction of a Secondary Metal Alkoxide with a Carbene to Produce a}

\section{Ketone $^{30}$.}

Based on the previously described literature, we theorized that we were producing 2butylcyclohexanone by first opening the epoxide ring of cyclohexene oxide by an $\mathrm{S}_{\mathrm{N}} 2$ substitution with $n$-butylpotassium to make the alkoxide of trans-2-butylcyclohexan-1-ol as predicted. Next, a second equivalent of $n$-butylpotassium reacted with cyclohexene oxide to produce a carbene alkoxide as postulated by Hodgson. Finally, the carbene alkoxide oxidized the alkoxide of trans-2-butylcyclohexan-1-ol to 2-butylcyclohexanone as observed in Oku's chemistry (Scheme 2.11). 


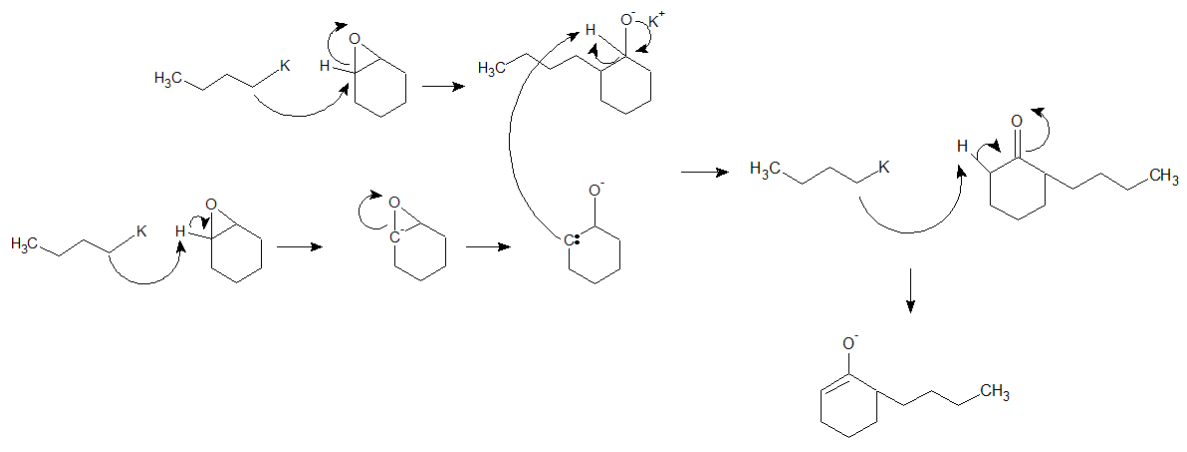

Scheme 2.11 Hypothesized Mechanism for the Production of 2-Butylcyclohexanone.

In an attempt to verify the presence of the carbene in the hypothesized mechanism, cyclohexanol was added to the reaction of cyclohexene oxide and $n$-butylpotassium, which is produced by the reaction of $n$-butyllithium with potassium tert-amylate. If the carbene was indeed being produced, cyclohexanol should have been converted to cyclohexanone through the reaction of a carbene with the alkoxide of cyclohexanol (Scheme 2.12).

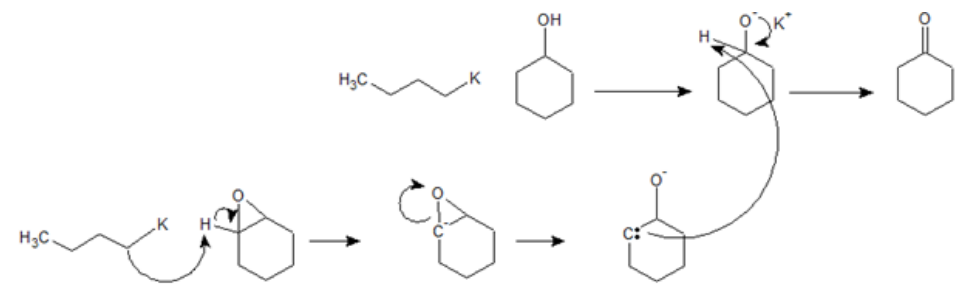

Scheme 2.12 Reaction of $\boldsymbol{n}$-Butylpotassium with Cyclohexene Oxide in the Presence of Cyclohexanol to Produce Cyclohexanone. 


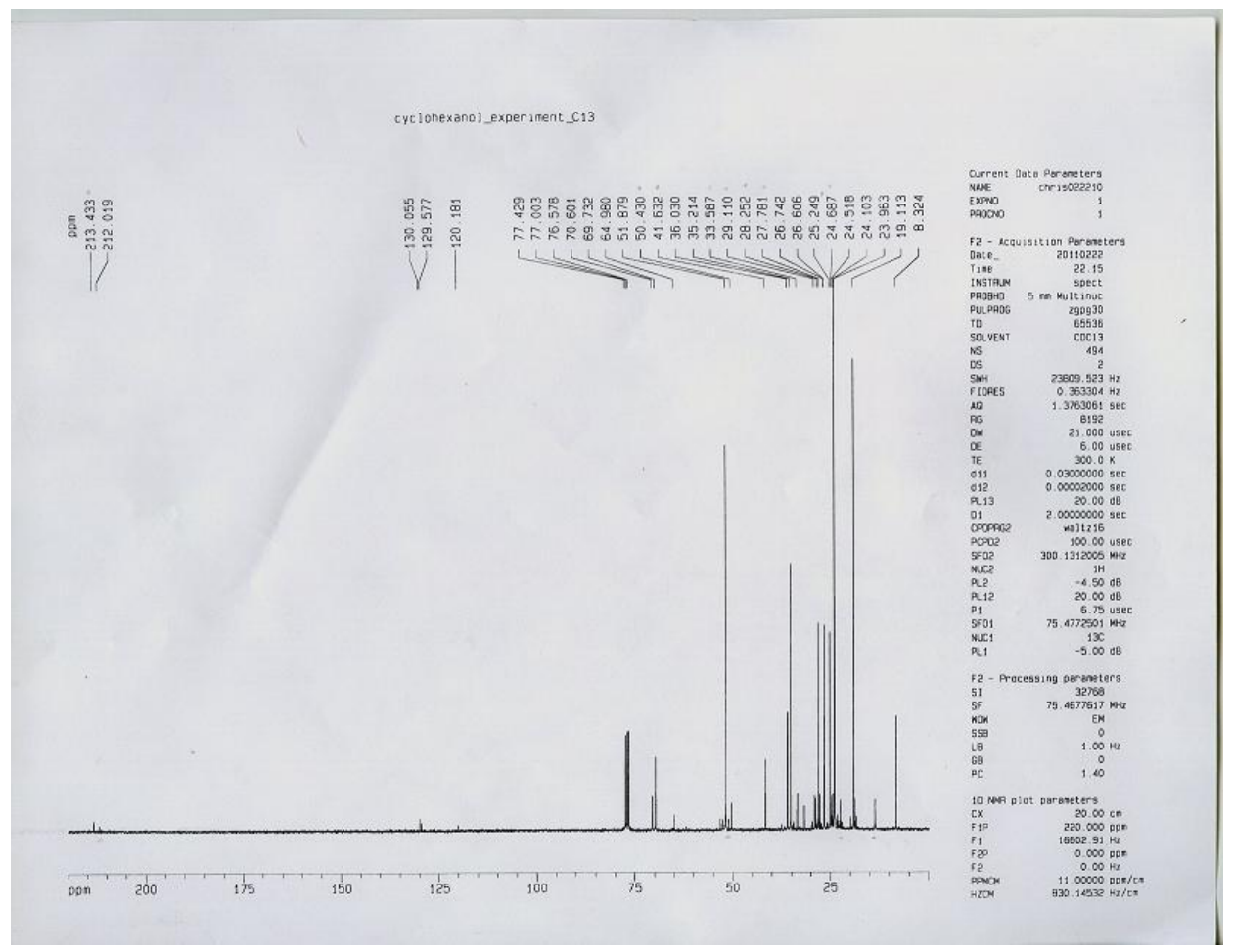

\section{Figure $2.17{ }^{13} \mathrm{C}$ NMR of Crude Product from the Reaction of $n$-Butylpotassium and Cyclohexene Oxide in the Presence of Cyclohexanol.}

After completion of the reaction, ${ }^{13} \mathrm{C}$ NMR was utilized to analyze the distilled product (Figure 2.17). There are two peaks at 213.4 and $212.0 \mathrm{ppm}$ that correspond to the carbonyl functionality. This led us to believe that not only were we producing the carbene but we were converting both the cyclohexanol and the predicted substitution product to ketones. In order to further verify these results we attempted to isolate these compounds utilizing thin layer chromatography, radial chromatography, and gas chromatography without any success. We believe this is due to the fact that these compounds are present in small amounts and are also volatile.

We continued to pursue the verification of the substitution mechanism by reaction of 1methyl-1,2-epoxycyclohexane with $n$-butylpotassium. The presence of the methyl group at the $\alpha$ - 
position should prevent the conversion of the epoxide to a ketone after substitution allowing us to "trap" the substitution product 2-butyl-1-methylcyclohexan-1-ol (Scheme 2.13).

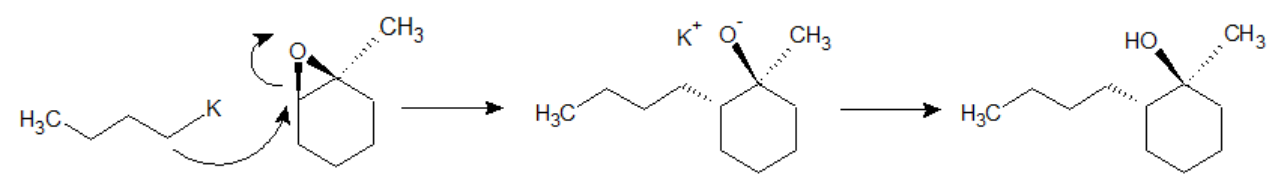

\section{Scheme 2.13 Reaction of 1-Methyl-1,2-Epoxycyclohexane with $n$-Butylpotassium to}

\section{Produce 2-Butyl-1-Methylcyclohexan-1-ol.}

${ }^{13} \mathrm{C}$ NMR analysis was completed on a sample of the product (Figure 2.18). The results of the ${ }^{13} \mathrm{C}$ NMR show a peak at $213.5 \mathrm{ppm}$ which corresponds to a carbonyl functionality. The purity of the 1-methyl-1,2-epoxycyclohexane and deuterated chloroform were verified to make sure that no ketone contaminant was present in these reagents. This ketone may be due to the rearrangement of the corresponding carbene of this epoxide following Hodgson's mechanism (Scheme 2.14).

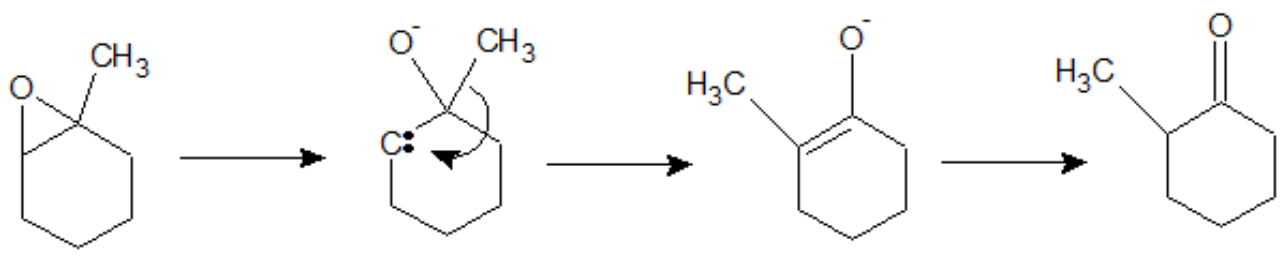

Scheme 2.14 Suspected Rearrangement of 1-Methyl-1,2-Epoxycyclohexane to the Corresponding Ketone. 


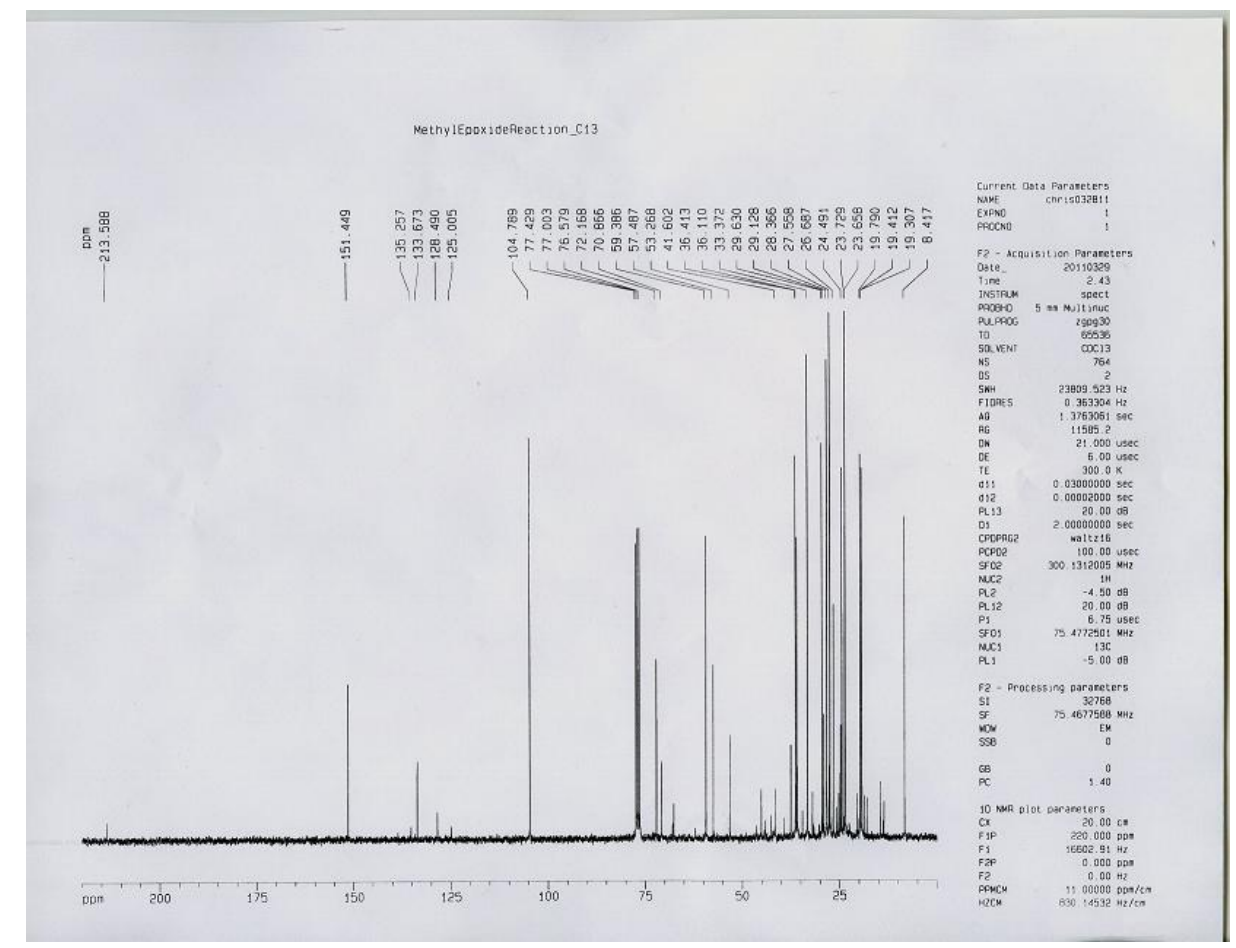

Figure 2.18 ${ }^{13} \mathrm{C}$ NMR of Crude Product from the Reaction of $n$-Butylpotassium with 1-

Methyl-1,2-Epoxycyclohexane.

\subsubsection{Reaction of sec-Butylpotassium and Cyclohexene Oxide}

To this point the focus of this work had been on tertiary and primary examples of organopotassium compounds with cyclohexene oxide. We wanted to attempt a reaction with a secondary organopotassium species to see if an epoxide ring opening reaction would occur. We utilized sec-butyllithium in order to produce sec-butylpotassium (Scheme 2.15) and reacted with cyclohexene oxide to observe its reactivity.<smiles>[X]OC(C)(C)CC</smiles><smiles>[X]C(C)CC</smiles>

Scheme 2.15 Production of sec-Butylpotassium. 


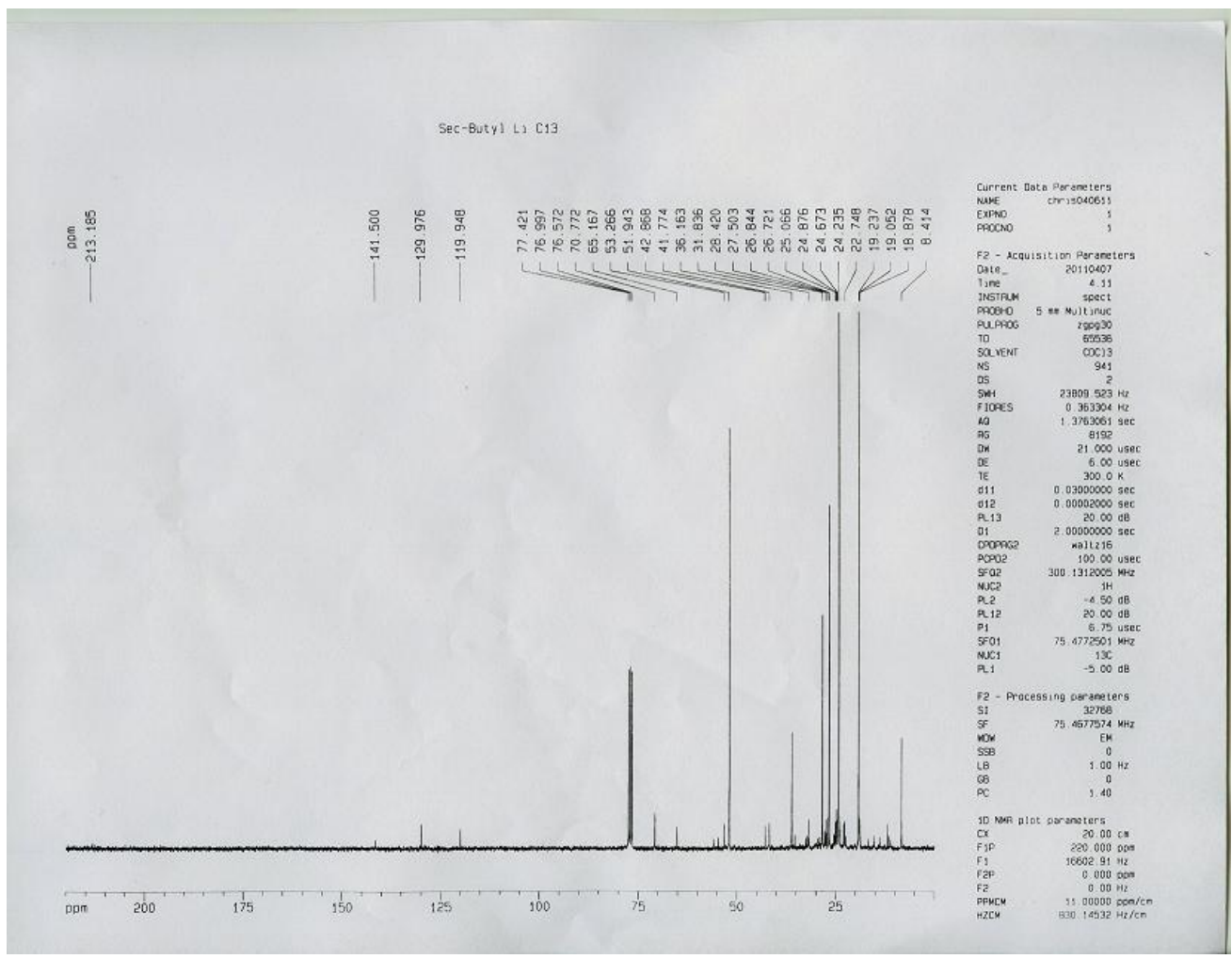

\section{Figure 2.19 ${ }^{13} \mathrm{C}$ NMR of Crude Product from the Reaction of sec-Butylpotassium and Cyclohexene Oxide.}

The reaction product was analyzed utilizing ${ }^{13} \mathrm{C}$ NMR (Figure 2.19). A small peak is formed at $213.1 \mathrm{ppm}$ that corresponds to a carbonyl functionality. The size of the carbonyl peak with relation to the rest of the peaks in the spectrum is small and leads us to believe that the ability to open the epoxide with a secondary carbanion is more difficult because of greater steric interactions. 


\section{Chapter 3: Conclusions}

Molecular modeling studies of the structure of $\alpha$-cumylpotassium in the presence of two equivalents of cumene show that the potassium ion interacts with the aromatic rings of the $\alpha$ cumyl anion and cumene making the benzilic carbon $s p^{2}$ hybridized in nature giving the $\alpha$-cumyl anion an overall flat shape. This makes it easy to react with an electrophile that can come in from either the top or the bottom of the molecule, making the $\alpha$-cumyl anion a more effective nucleophile (Figure 2.1). Molecular modeling studies done on $\alpha$-cumyllithium and sodium show that the metal ions interact with the benzilic position making it $s p^{3}$ hybridized in nature giving it a tetrahedral geometry that makes it more difficult for an electrophile to react because of steric interactions (Figures 2.2 and 2.3).

The reaction of $\alpha$-cumylpotassium and cyclohexene oxide produces transcumylcyclohexanol in high yield in the presence of three equivalents of cumene ${ }^{16}$. Based on the molecular modeling studies, we predicted that aromatic solvents such as benzene and tertbutylbenzene could effectively substitute cumene to give trans-cumylcyclohexanol in high yield but only obtained yields of $3 \%$ for the benzene substituted reaction and $27 \%$ for the tertbutylbenzene substituted reaction (Equations 2.1 and 2.2). The reaction done in the presence of benzene formed a precipitate that was partly the cause of the low yield. It is also possible that both the benzene and tert-butylbenzene reactions, which contained only one equivalent of cumene, were terminated too quickly and could have produced higher yields if allowed to react for more than two days as indicated by subsequent kinetic studies.

It was later determined that relatively high yields of trans-cumylcyclohexanol could be obtained in the presence of 1.1 or 2.0 equivalents of cumene over time (Tables 2.1 and 2.2), indicating that the high yield of the reaction is not due to the amount of cumene or aromatic 
solvent present but to the amount of time that the cumene is allowed to react with $n$ butylpotassium to produce $\alpha$-cumylpotassium. In other words this was an issue of kinetics. The decrease in yield after a week in the subsequent reactions of $\alpha$-cumylpotassium could be due to solvent evaporation, introduction of moisture from the air line, or the instability of $\alpha$ cumylpotassium as observed for $\alpha$-cumyllithium ${ }^{22}$ and sodium ${ }^{23}$. The next logical step would be to confirm if $\alpha$-cumylpotassium could be produced then stored in a sealed container and tested periodically to verify its stability. If it can be maintained over long periods of time it could be made commercially available.

The reactivity of a primary organopotassium species, $n$-butylpotassium, with cyclohexene oxide was studied. The reaction did not produce the predicted $\mathrm{S}_{\mathrm{N}} 2$ product, trans-2butylcyclohexan-1-ol, but gave 2-butylcyclohexanone (2\%). Derivatization to the corresponding semicarbazone further verified the identity of the product and the isolated yield was increased (10\%). The formation of 2-butylcyclohexanone was hypothesized to occur by oxidizing the $\mathrm{S}_{\mathrm{N}} 2$ product of $n$-butylpotassium and cyclohexene oxide (the alkoxide of trans-2-butylcyclohexan-1ol) with a carbene intermediate produced through the rearrangement of cyclohexene oxide with strong base ( $n$-butylpotassium), followed by protection of the ketone product (2butylcyclohexanone) as its enolate ${ }^{29,30}$ (Scheme 2.11).

Two possible reasons for the low yield: 1) The volatility of 2-butylcyclohexanone and 2) The incomplete isolation of the semicarbazone by recrystallization. More importantly, when we take into consideration that one equivalent of $n$-butylpotassium is used for the formation of the alkoxide of trans-2-butylcyclohexan-1-ol, a second equivalent for the creation of the carbene that oxidizes the alcohol to a ketone (2-butylcyclohexanone), and a third equivalent because ketones are easily enolized in the presence of a strong base; it becomes clear that at least three 
equivalents of $n$-butylpotassium are necessary and that the highest yield possible in the presence of one equivalent of $n$-butylpotassium would be $33 \%$ by the given mechanism (Scheme 2.11).

An attempt was made to verify the formation of a carbene by reacting $n$-butylpotassium and cyclohexene oxide in the presence of the alkoxide of cyclohexanol to make cyclohexanone by carbene oxidation. When potassium tert-amylate and $n$-butyllithium were added to a solution of cyclohexene oxide and cyclohexanol two carbonyl peaks were observed through ${ }^{13} \mathrm{C}$ NMR, which could correspond to 2-butylcyclohexanone and cyclohexanone. Unfortunately it was not possible to isolate or quantify the amount of cyclohexanone present. Other alcohol additives should be tested with the goal being their oxidation to suppress the formation of 2butylcyclohexanone so that trans-2-butylcyclohexan-1-ol can be isolated.

Because $n$-butyllithium was confirmed to produce a beta-elimination product with cyclohexene oxide (Scheme $1.2^{6}$ and Figure 2.11) and because the potassium-lithium exchange reaction that produces $n$-butylpotassium is an equilibrium, the reaction of $n$-butylpotassium without any lithium salts should be tested to see if more substitution versus elimination product can be formed.

Verification of the substitution mechanism was also attempted by reacting 1-methyl-1,2epoxycyclohexane with $n$-butylpotassium to produce the corresponding alcohol, 2-butyl-1methyl cyclohexan-1-ol. The presence of the methyl group at the $\alpha$ position of the epoxide was predicted to prevent the formation of the ketone but the ${ }^{13} \mathrm{C}$ NMR gave indication of a carbonyl group in the crude reaction mixture. This could be explained by a possible rearrangement mechanism involving the formation of a carbene followed by rearrangement of the methyl group (Scheme 2.14). The carbonyl containing products need to be isolated from both reactions to verify the mechanism. In addition, there may be a difficulty in the reaction regarding the axial 
versus the equatorial epoxide bonds as is observed in the preferred axial conformation for the reaction of limonene oxide diastereomers and $\alpha$-cumylpotassium ${ }^{31}$.

Cyclohexene oxide was reacted with sec-butylpotassium and the crude reaction mixture was analyzed by ${ }^{13} \mathrm{C}$ NMR to explore reactions beyond primary alkyl carbanions. The NMR spectrum showed that there was evidence of a carbonyl group but the intensity was extremely low compared to the other peaks in the spectrum. It is also interesting to postulate that if a carbene is being formed and abstracts a hydrogen from an alkoxide, the intermediate dianion could oxidize to cyclohexenol (Scheme 3.1) without requiring a beta elimination mechanism (Scheme 1.2).

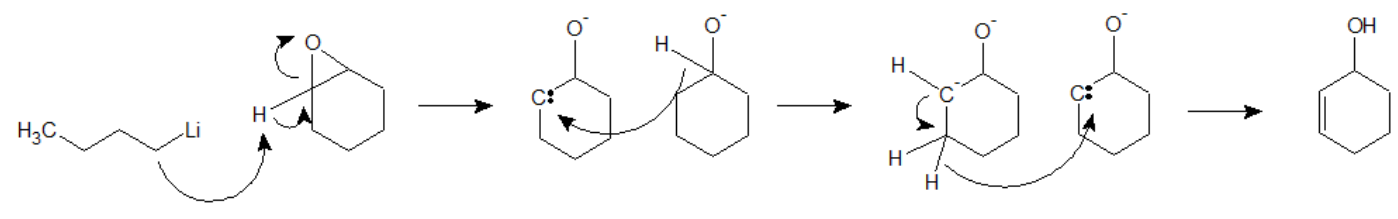

Scheme 3.1 Reaction of an Intermediate Dianion with a Carbene to Produce Cyclohexenol.

The findings in this research work give the scientific community another method for substitution of alkyl groups on epoxides without additives. It also gives insight into the differences of reactivity between potassium and other corresponding metals. 


\section{Chapter 4: Experimental}

\subsection{Materials}

Potassium tert-amylate was generously donated by BASF as K-tert-Amylate Solution $15 \%$ in cyclohexane. Cumene (98\%), cyclohexene oxide (98\%), $n$-butyllithium (2.5 $\mathrm{M}$ in hexanes), sec-butyllithium (1.3 M in hexanes), benzene, tert-butylbenzene (99\%), dichloromethane (99.6\%), hexanes (98.5\% CHROMASOLV), and 2-propanol $(99.9 \%$ CHROMASOLV) were purchased from the Sigma-Aldrich Company. Sodium Acetate was purchased from the Spectrum Chemical Manufacturing Corporation. Semicarbazide Hydrochloride was purchased from Mallinckrodt Incorporated. 1-Methyl-1,2-Epoxycyclohexane was purchased from TCI America.

\subsection{Equipment}

\subsubsection{Rotary Evaporator}

The Buchi R-110 Rotovapor rotoary evaporator from BUCHI, LABORATORLUMSTECKNIK AG, 70 Switzerland was utilized to remove volatile solvents from reaction mixtures.

\subsubsection{Horizontal Distillation}

The Kuelgrohr Horizontal Distillation Set-Up was utilized to remove high-boiling point solvents from reaction samples after using the rotary evaporator.

\subsubsection{Chiral Column High Preformance Liquid Chromatography}

Chiral Column High Performance Liquid Chromatography was utilized to quantify and identify TCC. A Chiralcel OJ column from Diacel Chemical Industries Inc. was employed. A Spectra-Physics Spectra System P1500 gradient pump was utilized with a 95\%/5\% hexanes/2- 
proponal mobile phase mixture. The UV2000 detector was set at $215 \mathrm{~nm}$ to avoid overlap with other compounds observed at $256 \mathrm{~nm}$. Samples of 1-3 $\mu \mathrm{L}$ were injected at room temperature.

\subsubsection{Radial Chromatography and UV Light}

Radial chromatography was utilized to separate crude reaction samples. A solution of 5\% ethyl acetate and $95 \%$ hexanes was used to moisten the plate and as the mobile phase. An aliquot of approximately $0.25 \mathrm{~g}$ was introduced to the $1 / 4$ inch silica plate as it rotated. The UVGL-15 Mineralight ${ }^{\circledR}$ multiband UV 254/366 nm $(115 \mathrm{~V}, 60 \mathrm{~Hz}, 0.16 \mathrm{amps})$ lamp was utilized to observe the product band as it eluded from the center to the outside of the plate.

\subsubsection{Melting-Point Apparatus}

A Mel-Temp ${ }^{\circledR}$ Electrothermal ${ }^{\circledR}$ melting-point apparatus was utilized to determine the melting point of isolated products packed to a height of at least $3 \mathrm{~mm}$ in melting point tubes. An un-calibrated Celsius mercury thermometer was utilized to measure the temperature.

\subsubsection{Nuclear Magnetic Resonance (NMR)}

A Bruker-Spectrospin $300 \mathrm{MHz}$ NMR was utilized to obtain Carbon-13 $\left({ }^{13} \mathrm{C}\right)$, Proton

$\left({ }^{1} \mathrm{H}\right)$, and Distortionless Enhancement by Polarization Transfer-135 ${ }^{\circ}$ (DEPT-135) spectrum of crude reaction samples and isolated products. Deuterated chloroform $\left(\mathrm{CDCl}_{3}\right)$ with tetramethylsilane was utilized as the solvent for the NMR sample.

\subsubsection{Mass Spectrometer}

The JEOL AccuTOF JMS-T100LC and Direct Analysis in Real Time (DART) Ion Sense in positive ion mode $[\mathrm{M}+\mathrm{H}]+$ were utilized to obtain the mass spectrum of the crude reaction mixture containing 2-butylcyclohexanone. 


\subsection{Experimental}

\subsubsection{Attempted Synthesis of trans-Cumylcyclohexanol in the Presence of Benzene}

To a clean and dry $100 \mathrm{~mL}$ round bottom flask, with magnetic stir bar, and rubber septum was added $10 \mathrm{~mL}$ of $1.2 \mathrm{M}$ potassium tert-amylate $(12 \mathrm{mmol}), 1.4 \mathrm{~mL}$ of cumene $(10 \mathrm{mmol})$, and $2.7 \mathrm{~mL}$ of benzene $(30 \mathrm{mmol})$ via syringe under nitrogen gas. To the flask was added $5 \mathrm{~mL}$ of 2.5 $\mathrm{M} \mathrm{n}$-butyllithium (12.5 $\mathrm{mmol})$ dropwise to remove all traces of moisture as indicated by a color change. After two days, the reaction formed a brown precipitate and $1 \mathrm{~mL}$ of cyclohexene oxide $(10 \mathrm{mmol})$ was added dropwise. The reaction was stirred a further two hours becoming dark. $30 \mathrm{~mL}$ of de-ionized water were added and the yellow organic layer was washed with more water $(2 \mathrm{x} 30 \mathrm{~mL})$. The combined aqueous layers were extracted with dichloromethane $(3 \mathrm{x}$ $30 \mathrm{~mL}$ ) and the combined organic layers were dried over potassium carbonate and decanted into a round bottom flask. The solvent was removed via vacuum distillation on a rotary evaporator and the remaining yellow oil was distilled bulb to bulb. Chiral column High Performance Liquid Chromatography (HPLC) was performed on the distillate to identify and quantify the percent yield of TCC as follows: to a $15 \mathrm{~mL}$ volumetric flask was added $0.600 \mathrm{~g}$ of crude sample and hexanes. $3 \mu \mathrm{L}$ of this solution was injected into the HPLC with a mobile phase of $95 \%$ hexanes to $5 \%$ isopropanol and a velocity of $1 \mathrm{~mL} / \mathrm{min}$. A wavelength of $215 \mathrm{~nm}$ was used for the measurement because at $256 \mathrm{~nm}$ the enantiomer areas were not equal indicating overlap of other products with the second peak. A standard solution was prepared using $0.122 \mathrm{~g}$ of purified TCC added to a $10 \mathrm{~mL}$ volumetric flask that was then filled to the line with hexanes. $1 \mu \mathrm{L}$ of this solution was analyzed by HPLC. Once the HPLC results for TCC synthesized with benzene solvent and the standard were obtained, dimensional analysis was utilized to determine that the percentage yield was $3 \%$. 


\subsubsection{Attempted Synthesis of trans-Cumylcyclohexanol in the Presence of tert- butylbenzene}

Two equivalents tert-butylbenzene $(20 \mathrm{mmol})$ were used in the same reaction sequence as previously described for benzene. HPLC analysis was performed on a sample of $0.134 \mathrm{~g}$ of the tert-butylbenzene derived TCC and hexanes in a $10 \mathrm{~mL}$ volumetric flask.

\subsubsection{Synthesis of trans-Cumylcyclohexanol with 1.1 Equivalents of Cumene}

Day 2. To a clean and dry $100 \mathrm{~mL}$ round bottom flask, with magnetic stir bar, and rubber septum was added $10 \mathrm{~mL}$ of $1.2 \mathrm{M}$ potassium tert-amylate $(12 \mathrm{mmol})$ and $1.5 \mathrm{~mL}$ of cumene $(11$ mmol) via syringe under nitrogen gas. To the flask was added $4 \mathrm{~mL}$ of $2.5 \mathrm{M} n$-butyllithium (10 mmol) dropwise to remove all traces of moisture as indicated by a color change. After two days, the reaction formed a brown precipitate and $1 \mathrm{~mL}$ of cyclohexene oxide $(10 \mathrm{mmol})$ was added dropwise. The reaction was stirred a further two hours becoming dark. $30 \mathrm{~mL}$ of de-ionized water were added and the yellow organic layer was washed with more water $(2 \mathrm{x} 30 \mathrm{~mL})$. The combined aqueous layers were extracted with dichloromethane $(3 \mathrm{x} 30 \mathrm{~mL})$ and the combined organic layers were dried over potassium carbonate and decanted into a round bottom flask. The solvent was removed via vacuum distillation on a rotary evaporator and the remaining yellow oil was distilled bulb to bulb utilizing a Kugelrohr apparatus to give $1.05 \mathrm{~g}(49 \%)$ of crude product as viscous oil.

Day 4. The reaction was set up in the same manner as the Day 2 experiment. After four days cyclohexne oxide was added $(10 \mathrm{mmol})$. The work up was performed as previously described to give $1.44 \mathrm{~g}(67 \%)$ of crude product as viscous oil. 
Day 6. The reaction was set up in the same performed as the Day 2 experiment. After six days cyclohexne oxide was added $(10 \mathrm{mmol})$. The work up was performed as previously described to give $1.47 \mathrm{~g}(68 \%)$ of crude product as viscous oil.

Day 8. The reaction was set up in the same manner as the Day 2 experiment. After eight days cyclohexne oxide was added $(10 \mathrm{mmol})$. The work up was performed as previously described to give $1.58 \mathrm{~g}(74 \%)$ of crude product as viscous oil.

Day 10. The reaction was set up in the same manner as the Day 2 experiment. After ten days cyclohexne oxide was added $(10 \mathrm{mmol})$. The work up was performed as previously described to give $1.44 \mathrm{~g}(67 \%)$ of crude product as viscous oil.

\subsubsection{Synthesis of trans-Cumylcyclohexanol with 2.0 Equivalents of Cumene}

Day 1 . To a clean and dry $100 \mathrm{~mL}$ round bottom flask, with magnetic stir bar, and rubber septum was added $10 \mathrm{~mL}$ of $1.2 \mathrm{M}$ potassium tert-amylate $(12 \mathrm{mmol})$ and $2.25 \mathrm{~g}$ of cumene (18.8 mmol) via syringe under nitrogen gas. To the flask was added $4 \mathrm{~mL}$ of $2.5 \mathrm{M} n$ butyllithium $(10 \mathrm{mmol})$ dropwise to remove all traces of moisture as indicated by a color change. After one day, the reaction formed a brown precipitate and $0.88 \mathrm{~g}$ of cyclohexene oxide $(9.88$ mmol) was added dropwise. The reaction was stirred a further two hours becoming dark. $30 \mathrm{~mL}$ of de-ionized water were added and the yellow organic layer was washed with more water $(2 \mathrm{x}$ $30 \mathrm{~mL})$. The combined aqueous layers were extracted with dichloromethane $(3 \mathrm{x} 30 \mathrm{~mL})$ and the combined organic layers were dried over potassium carbonate and decanted into a round bottom flask. The solvent was removed via vacuum distillation on a rotary evaporator and the remaining yellow oil was distilled bulb to bulb utilizing a Kugelrohr apparatus to give $1.27 \mathrm{~g}(65 \%)$ of crude product as viscous oil. 
Day 2. To a clean and dry $100 \mathrm{~mL}$ round bottom flask, with magnetic stir bar, and rubber septum was added $10 \mathrm{~mL}$ of $1.2 \mathrm{M}$ potassium tert-amylate $(11.5 \mathrm{mmol})$ and $2.30 \mathrm{~g}$ of cumene (19.2 mmol) via syringe under nitrogen gas. To the flask was added $4.6 \mathrm{~mL}$ of $2.5 \mathrm{M} n$ butyllithium (12 mmol) dropwise to remove all traces of moisture as indicated by a color change. After two days, the reaction formed a brown precipitate and $0.99 \mathrm{~g}$ of cyclohexene oxide $(10.1$ mmol) was added dropwise. The reaction was stirred a further two hours becoming dark. $30 \mathrm{~mL}$ of de-ionized water were added and the yellow organic layer was washed with more water $(2 \mathrm{x}$ $30 \mathrm{~mL})$. The combined aqueous layers were extracted with dichloromethane $(3 \mathrm{x} 30 \mathrm{~mL})$ and the combined organic layers were dried over potassium carbonate and decanted into a round bottom flask. The solvent was removed via vacuum distillation on a rotary evaporator and the remaining yellow oil was distilled bulb to bulb utilizing a Kugelrohr apparatus to give $1.55 \mathrm{~g}$ (71\%) of crude product as viscous oil.

Day 4. The reaction was set up in the same manner as the Day 2 experiment. After four days $0.99 \mathrm{~g}$ of cyclohexne oxide $(10.1 \mathrm{mmol})$ was added dropwise. The work up was performed as previously described to give $1.57 \mathrm{~g} \mathrm{(71 \% )} \mathrm{of} \mathrm{crude} \mathrm{product} \mathrm{as} \mathrm{viscous} \mathrm{oil.}$

Day 6. To a clean and dry $100 \mathrm{~mL}$ round bottom flask, with magnetic stir bar, and rubber septum was added $10 \mathrm{~mL}$ of $1.2 \mathrm{M}$ potassium tert-amylate $(12 \mathrm{mmol})$ and $2.32 \mathrm{~g}$ of cumene (19.3 mmol) via syringe under nitrogen gas. To the flask was added $4.8 \mathrm{~mL}$ of $2.5 \mathrm{M} \mathrm{n}$ butyllithium (12 mmol) dropwise to remove all traces of moisture as indicated by a color change. After six days, the reaction formed a brown precipitate and $0.99 \mathrm{~g}$ of cyclohexene oxide $(10.1$ mmol) was added dropwise. The reaction was stirred a further two hours becoming dark. $30 \mathrm{~mL}$ of de-ionized water were added and the yellow organic layer was washed with more water $(2 x$ $30 \mathrm{~mL})$. The combined aqueous layers were extracted with dichloromethane $(3 \mathrm{x} 30 \mathrm{~mL})$ and the 
combined organic layers were dried over potassium carbonate and decanted into a round bottom flask. The solvent was removed via vacuum distillation on a rotary evaporator and the remaining yellow oil was distilled bulb to bulb utilizing a Kugelrohr apparatus to give $1.51 \mathrm{~g}(69 \%)$ of crude product as viscous oil.

Day 8. The reaction was set up in the same manner as the Day 6 experiment. After eight days $0.99 \mathrm{~g}$ of cyclohexne oxide $(10.1 \mathrm{mmol})$ was added dropwise. The work up was performed as previously described to give $1.58 \mathrm{~g}(72 \%)$ of crude product as viscous oil.

Day 10. The reaction was set up in the same manner as the Day 2 experiment. After ten days $1.04 \mathrm{~g}$ of cyclohexne oxide $(10.6 \mathrm{mmol})$ was added dropwise. The work up was performed as previously described to give $1.33 \mathrm{~g}(57.8 \%)$ of crude product as viscous oil.

\subsubsection{Synthesis of 2-Butylcyclohexanone}

To a clean and dry $100 \mathrm{~mL}$ round bottom flask, with magnetic stir bar, and rubber septum was added $40 \mathrm{~mL}$ of $1.2 \mathrm{M}$ potassium tert-amylate $(48 \mathrm{mmol})$ and $16 \mathrm{~mL}$ of $2.5 \mathrm{M} \mathrm{n}$ butyllithium (40 mmol) dropwise via syringe under nitrogen gas. After fifteen minutes, the reaction formed a white precipitate and $3.74 \mathrm{~g}$ of cyclohexene oxide $(38.1 \mathrm{mmol})$ was added dropwise. The reaction was stirred a further two hours then $30 \mathrm{~mL}$ of de-ionized water were added and the yellow organic layer was washed with more water $(2 \mathrm{x} 30 \mathrm{~mL})$. The combined aqueous layers were extracted with dichloromethane $(3 \times 30 \mathrm{~mL})$ and the combined organic layers were dried over potassium carbonate and decanted into a round bottom flask. The solvent was removed via vacuum distillation on a rotary evaporator and the remaining light yellow oil was distilled bulb to bulb utilizing a Kugelrohr apparatus to give $1.18 \mathrm{~g}$ of crude product. Radial Chromatography was performed on the distillate to identify and quantify the percent yield of 2butylcyclohexanone as follows: A 5\% ethyl acetate/hexane solution was prepared and utilized to 
moisten the $1 / 4$ inch rotating silica plate. To the moistened silica plate was added $0.28 \mathrm{~g}$ of crude sample. An Ultraviolet light was utilized to observe and collect the first band as it eluted from the plate. The solvent was evaporated utilizing aspirator pressure giving $0.03 \mathrm{~g}(2 \%)$ of isolated product. The ${ }^{1} \mathrm{H}$ NMR, ${ }^{13} \mathrm{C}$ NMR and Mass Spectrum Analysis coincide with the literature ${ }^{12}$.

\subsubsection{Synthesis of 2-Butylcyclohexanone Semicarbazone}

To a clean and dry $100 \mathrm{~mL}$ round bottom flask, with magnetic stir bar, and rubber septum was added $10 \mathrm{~mL}$ of $1.2 \mathrm{M}$ potassium tert-amylate $(12 \mathrm{mmol})$ and $0.99 \mathrm{~g}$ of cyclohexene oxide $(10.1 \mathrm{mmol})$ via syringe under nitrogen gas. To the flask was added $4 \mathrm{~mL}$ of $2.5 \mathrm{M} \mathrm{n}$ butyllithium $(10 \mathrm{mmol})$ dropwise. The reaction was stirred further 1 hour then $30 \mathrm{~mL}$ of deionized water were added and the yellow organic layer was washed with more water $(2 \times 30 \mathrm{~mL})$. The combined aqueous layers were extracted with hexane $(3 \mathrm{x} 30 \mathrm{~mL})$ and the combined organic layers were poured into a $250 \mathrm{~mL}$ round bottom flask. To the flask was added $1.57 \mathrm{~g}$ of sodium acetate and $0.98 \mathrm{~g}$ semicarbazide and shaken vigorously until a white solid formed. The remaining solvent was evaporated via vacuum distillation on a rotary evaporator and the remaining light yellow oil was allowed to cool until crystals formed. The remaining crystals were then washed with cold ethanol to give $0.19 \mathrm{~g}$ of semicarbazone or $0.154 \mathrm{~g} \mathrm{2-}$ butylcyclohexanone $(10 \%)$. The semicarbazone was recrystallized using ethanol to give fine white crystals: $\mathrm{mp} .134^{\circ} \mathrm{C}$ (lit. mp. $\left.138.5-139.5^{\circ} \mathrm{C}\right){ }^{13} \mathrm{C}$ NMR $\left(\mathrm{CDCl}_{3}\right) \delta=14.105,22.867$, 23.754, 25.144, 26.306, 29.458, 30.700, 33.018, 43.996, 155.652, 157.915.

\subsubsection{Attempted Synthesis of Cyclohexanone}

To a clean and dry $100 \mathrm{~mL}$ round bottom flask, with magnetic stir bar, and rubber septum was added $1 \mathrm{~mL}$ of cyclohexanol (10 mmol), $2 \mathrm{~mL}$ of cyclohexene oxide (20 mmol), $24 \mathrm{~mL}$ of 1.2 M potassium tert-amylate $(24 \mathrm{mmol})$ via syringe under nitrogen gas. To the flask was added 
$8 \mathrm{~mL}$ of $2.5 \mathrm{M} n$-butyllithium ( $20 \mathrm{mmol}$ ) dropwise. The reaction was stirred further 1 hour then $30 \mathrm{~mL}$ of de-ionized water were added and the yellow organic layer was washed with more water $(2 \times 30 \mathrm{~mL})$. The combined aqueous layers were extracted with dichloromethane $(3 \mathrm{x} 30 \mathrm{~mL})$ and the combined organic layers were dried over potassium carbonate and decanted into a round bottom flask. The solvent was removed via vacuum distillation on a rotary evaporator to give the remaining crude product as a viscous slightly yellow oil.

\subsubsection{Attempted Synthesis of 2-Butyl-1-Methylcyclohexan-1-ol}

To a clean and dry $100 \mathrm{~mL}$ round bottom flask, with magnetic stir bar, and rubber septum was added $10 \mathrm{~mL}$ of $1.2 \mathrm{M}$ potassium tert-amylate $(12 \mathrm{mmol})$ and $1.2 \mathrm{~mL}$ of 1-methyl-1,2epoxycyclohexane $(9.96 \mathrm{mmol})$ via syringe under nitrogen gas. To the flask was added $4 \mathrm{~mL}$ of 2.5 M $n$-butyllithium (10 mmol) dropwise. The reaction was stirred further 1 hour then $30 \mathrm{~mL}$ of de-ionized water were added and the yellow organic layer was washed with more water $(2 \mathrm{x}$ $30 \mathrm{~mL})$. The combined aqueous layers were extracted with dichloromethane $(3 \times 30 \mathrm{~mL})$ and the combined organic layers were dried over potassium carbonate and decanted into a round bottom flask. The solvent was removed via vacuum distillation on a rotary evaporator to give the remaining crude product as a viscous yellow oil.

\subsubsection{Reaction of sec-Butylpotassium and Cyclohexene Oxide}

To a clean and dry $100 \mathrm{~mL}$ round bottom flask, with magnetic stir bar, and rubber septum was added $10 \mathrm{~mL}$ of $1.2 \mathrm{M}$ potassium tert-amylate $(12 \mathrm{mmol})$ and $1.0 \mathrm{~mL}$ of cyclohexene oxide $(9.88 \mathrm{mmol})$ via syringe under nitrogen gas. To the flask was added $7.6 \mathrm{~mL}$ of $2.5 \mathrm{M} \mathrm{sec}$-butyllithium $(9.88 \mathrm{mmol})$ dropwise. The reaction was stirred further 1 hour then 30 $\mathrm{mL}$ of de-ionized water were added and the yellow organic layer was washed with more water $(2 \times 30 \mathrm{~mL})$. The combined aqueous layers were extracted with dichloromethane $(3 \times 30 \mathrm{~mL})$ and 
the combined organic layers were dried over potassium carbonate and decanted into a round bottom flask. The solvent was removed via vacuum distillation on a rotary evaporator to give the remaining crude product as a viscous yellow oil. 


\section{References}

${ }^{1}$ Schneider, C. "Synthesis of 1,2-Difunctionalized Fine Chemicals Through Catalytic, Enantioselective Ring-Opening Reactions of Epoxides" Synthesis, 2006, 23, 3919-44.

${ }^{2}$ Fleck, M.; Bach, T. "Total Synthesis of the Tetracyclic Sesquiterpene ( \pm )-Puctaporonin C" Angewandte Chemie, International Edition, 2008, 47, 6189-91.

${ }^{3}$ Sicherl, F.; Cupido, T.; Albericio, F. “A Novel Dipeptidomimietic Containing a Cyclic Threonine" Chemical Communications, 2010, 46, 1266-8.

${ }^{4}$ Zweifel, G.S.; Nantz, M.H. “Modern Organic Synthesis: An Introduction” W.H. Freeman and Company, New York, 2007.

${ }^{5}$ Hodgson, D.M.; Flemming, M.J.; Stanway, S.J. "The Reactivity of Epoxides with Lithium 2,2,6,6-Tetramethylpiperidine in Combination with Organolithiums or Grignard Reagents" J. Org. Chem. 2007, 72, 4763-73.

${ }^{6}$ Wakefield, B.J., "The Chemistry of Organolithium Compounds" Pergamon Press, New York, 1974.

${ }^{7}$ Eis, M.J.; Wrobel, J.E.; Ganem, B. "Mechanism and Synthetic Utility of Boron Trifluoride Etherate Promoted Organolithium Additions" J. Am. Chem. Soc. 1984, 106, 3693-4.

${ }^{8}$ Lipshutz, Bruce H. "Reactions of Stoichiometric Higher Order, Mixed Lithiomagnesioorganocuprates" Tetrahedron Letters, 1986, 42(11), 2873-9.

${ }^{9}$ Smith, R.: Trzoss, M.; Buhl, M.; Bienz, S. “The Cram Rule Revisted Once More-Revision of the Felkin-Anh Model”. European Journal of Organic Chemistry, 2002,(16), 2770-5.

${ }^{10}$ Huynh, C.; Derguini-Boumechal, F.; Linstrumelle, G. "Copper-Catalysed Reactions of Grignard Reagents with Epoxides and Oxetane". Tetrahedron Letters, 1979, (17), 15036.

${ }^{11}$ Schlosser, M., Strunk, S. "The "Super-Basic" Butyl-Lithium/Potassium tert-Butoxide Mixture and Other LiCKOR-Reagents" Tetrahedron Letters, 1984, 25(7), 741-4.

${ }^{12}$ Osborne, A.G.; Whiteley, R.H. "Metallation of Ferrocene with $n$-Butylpotassium" Journal of Organometallic Chemistry, 1978, 162, 79-81.

${ }^{13}$ Broaddus, C.D. "A Comparison of Alkyl-Potassium and Alkylsodium Reagents in Metallation of $\alpha$-Olefins" The Journal of Organic Chemistry, 1964, 29(9), 2689-93. 
${ }^{14}$ Pi, R.; Bauer, W.; Brix, B.; Schade, C.; Von Rauge Schleyer, P. “ $n$-Butylpotassium: Preparation, Synthetic Use and NMR Properties in Hexane and Tetrahydrofuran Solution" Journal of Organometallic Chemistry, 1986, 306, C1-4.

${ }^{15}$ Lehmann, R.; Schlosser, M. "Facile Hydrogen/Metal Exchange Between Butylpotassium and Saturated Ethers" Tetrahedron Letters, 1984, 25(7), 745-8.

${ }^{16}$ Comins, D.L.; Salvador, J.M. "Efficient Synthesis and Resolution of trans-2-(1-Aryl-1methylethyl)cyclohexanols: Practical Alternatives to 8-Phenylmenthol" J. Org. Chem., 1993, 58, 4656.

${ }^{17}$ Benkeser, R.A.; Hooz, J.; Liston, T.V.; Trevillyan, A.E. "Factors Governing Orientation in Metalation Reactions. II. The Metalation of Isopropylbenzene with $n$-Amylsodium and $n$ Amylpotassium" J. Am. Chem. Soc., 1963, 85, 3984-89.

${ }^{18}$ Lee, H.S.; Niemeyer, M. "Inverse Aggregation Behavior of Alkali-Metal Triazenides." Inorganic Chemistry 2006, 45, 6126-8.

${ }^{19}$ Chen, X.; Liu, S.; Du, B.; Meyers, E.A. "The Structure of Potassium and Tetramethylammonium Salts of the Cyclic Organohydroborate Anion $\left[\mathrm{H}_{2} \mathrm{BC}_{8} \mathrm{H}_{14}\right]^{-}$with Different Solvent Ligands.” Eur. J. Inorg. Chem. 2007, 5563.

${ }^{20}$ Bryan, J.C.; Delmau, L.H.; Hay, B.P.; Nicholas, J.B.; Rogers, L.M.; Rogers, R.D., Moyer, B.A. "Cesium Recognition by Supramolecular Assemblies of 2-Benzylphenol and 2Benzylphenolate." Struct. Chem. 1999, 10, 187-203.

${ }^{21}$ Braunschweig, H.; Chiu, C-W.; Radacki, K.; Kupfer, T. "Synthesis and Structure of a Carbene-Stabilized $\pi$-Boryl Anion” Angew. Chemie., Int. Ed. 2010, 49, 2041-4.

${ }^{22}$ Screttas, C.G.; Heropoulos, G.A.; Micha-Screttas, M.; Steele, B.R.; Catsoulacos, D.P. "Reductive Lithiation of Alkyl Phenyl Sulfides in Diethyl Ether. A Ready Access to $\alpha, \alpha-$ Dialkylbenzyllithiums.” Tettrahedron Lett. 2003, 44, 5633-5.

${ }^{23}$ Crimmins, T.F.; Chan, C.M. "Metalation of Cumene with n-Pentylsodium in the Presence of N,N,N',N'-Tetramethylethylenediamine. Preparation of $\alpha$-Cumylsodium." J. Org. Chem. 1976, 41, 1870-2.

${ }^{24}$ Malosh, C.F.; Ready, J.M. "Catalytic Cross-Coupling of Alkylzinc Halides with $\alpha$ Chloroketones”. J. Am. Chem. Soc., 2004, 126, 10240-1.

${ }^{25}$ Holmquist, H.E. "Some Decomposition and Rearrangement Products of Decahydronaphthalene Hydroperoxide" Journal of the American Chemical Society 1956, $78,5339-41$. 
${ }^{26}$ Tiffeneau, M. "The Magnesium Dehalogenation of cis-Chlorohydrins of $\alpha$-Substituted Cyclohexanediols. Exclusive Formation of Alkylcyclohexanones Through a Semipinacolone Rearrangement" Compt. Rend. 1943, 216, 856-60.

${ }^{27}$ Cologne, J. " $\delta$-Oxo aldehydes. I. Preparation" Bulletin de la Societe Chemique de France 1959, 370-3, 450-2.

${ }^{28}$ Ritchie, E. "The Preparation of 2-Alkylcyclohexanones" Australian Journal of Chemistry 1964, 17(2), 281-2.

${ }^{29}$ Hodgson, D.M.; Robinson, L.A.; Jones, M.L. "On the Mechanism of Base-Induced Rearrangements of Epoxides to Ketones: A Formal Synthesis of (S)-physoperuvine." Tettrahedron Lett. 1999, 40, 8637-40.

${ }^{30}$ Oku, A.; Harada, T.; Hattori, K.; Nozaki, Y.; Yamaura, Y. "Stereochemical Aspects in the Insertion by Alkylidenemethylene Carbenoids into the $\alpha-\mathrm{C}-\mathrm{H}$ Bond of Alkoxides." $J$. Org. Chem. 1988, 53, 3089-98.

${ }^{31}$ Comins, D.L.; Guerra-Weltzien, L.; Salvador, J.M. "A Practical Synthesis of CyclohexylBased Chiral Auxiliaries from Limonene Oxide" Synlett 1994, 974. 


\section{Curriculum Vitae}

Christina was born in El Paso, Texas to Raul Ruben and Maria Cristina Alvarado. She graduated from Riverside High School, El Paso, Texas in the spring of 2003. She attended the University of Texas at El Paso (UTEP) in the fall of 2003 with generous support from the Ysleta Education Foundation Scholarship and the UTEP Presidential Excellence Scholarship. She graduated Magna Cum Laude with a Bachelor of Science degree in chemistry in the spring of 2007. Christina entered the UTEP Chemistry Ph.D program that fall. During her first year of graduate study she worked as a teaching assistant instructor for the organic chemistry lab and began work as a research assistant in the lab of her advisor Dr. James M. Salvador. She received generous support from the Louis Stokes Alliance for Minority Participation Bridge to the Doctorate Fellowship and UTEP Graduate School. She has presented her work at the American Chemical Society (ACS) $239^{\text {th }}$ National Meeting, San Francisco, California and the ACS $65^{\text {th }}$ Southwest Regional Meeting, El Paso, Texas. She has also presented her work at the Society for Advancement of Chicanos and Native Americans in Science (SACNAS) University of Texas at El Paso Chapter Conference, El Paso, Texas.

Permanent Address: 11417 Lake Geneva

El Paso, Texas 79936 